\title{
Nanoparticles as therapeutic options for treating multidrug-resistant bacteria: research progress, challenges, and prospects
}

\author{
Ifeanyi E. Mba ${ }^{1} \cdot$ Emeka I. Nweze $^{1}{ }^{10}$
}

Received: 20 March 2021 / Accepted: 16 May 2021 / Published online: 28 May 2021

(c) The Author(s), under exclusive licence to Springer Nature B.V. 2021

\begin{abstract}
Resistance to antimicrobial agents has been alarming in recent years and poses a huge public health threat globally according to the WHO. The increase in morbidity and mortality resulting from microbial infections has been attributed to the emergence of multidrug-resistant microbes. Associated with the increase in multidrug resistance is the lack of new and effective antimicrobials. This has led to global initiatives to identify novel and more effective antimicrobial agents in addition to discovering novel and effective drug delivery and targeting methods. The use of nanoparticles as novel biomaterials to fully achieve this feat is currently gaining global attention. Nanoparticles could become an indispensable viable therapeutic option for treating drug-resistant infections. Of all the nanoparticles, the metals and metal oxide nanoparticles appear to offer the most promise and have attracted tremendous interest from many researchers. Moreover, the use of nanomaterials in photothermal therapy has received considerable attention over the years. This review provides current insight on antimicrobial resistance as well as the mechanisms of nanoparticle antibacterial activity. It offers an in-depth review of all the recent findings in the use of nanomaterials as agents against multi-resistant pathogenic bacteria. Also, nanomaterials that can respond to light stimuli (photothermal therapy) to kill microbes and facilitate enhanced drug delivery and release are discussed. Moreover, the synergistic interactions of nanoparticles with antibiotics and other nanomaterials, microbial adaptation strategies to nanoparticles, current challenges, and future prospects were extensively discussed.
\end{abstract}

Emeka I. Nweze

emeka.nweze@unn.edu.ng

1 Department of Microbiology, University of Nigeria, Nsukka, Nigeria 


\section{Graphic abstract}

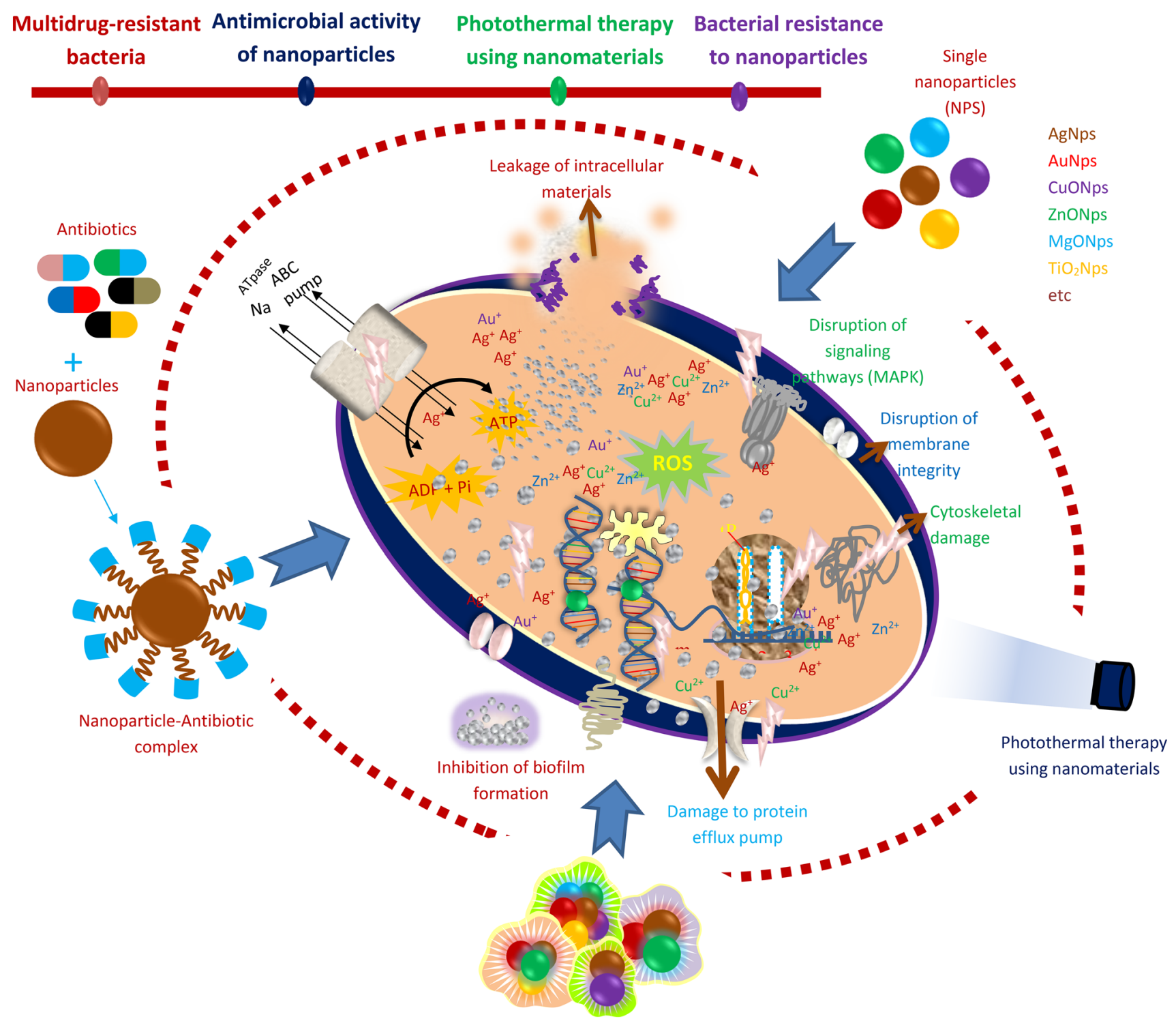

Nanocomposites

Keywords Nanoparticles - Antimicrobial resistance Conjugated nanoparticles/nanocomposites · Photothermal therapy · Antibacterial activity $\cdot$ Bacterial resistance to nanoparticles

\section{Introduction}

Nanoparticles are biomaterials with dimensions between 1 and $100 \mathrm{~nm}(\mathrm{~nm})$. Considerable attention has been given to nanomaterials due to their wide application in agriculture, pharmaceuticals, consumer products, transportation, energy, cosmetics, and more importantly as antimicrobial agents. They are currently regarded as viable substitutes and/ or supplements to existing antimicrobials ( $\mathrm{Li}$ et al. 2017).
Generally, nanoparticles' antimicrobial or biomedical properties depend on their methods of synthesis and formulation conditions, such as the nature of the reducing agent, temperature, concentration, and solvent type (Lee et al. 2019; Qing et al. 2018; Kedziora et al. 2018). The actions and activity of these nanoparticles also mostly depend on their chemical composition, shape and size (Shobha et al. 2014). Several conditions and parameters need to be modified and varied to produce a nanoparticle with effective size, distribution, 
morphologies, and yield. Factors like temperature, $\mathrm{pH}$ and metal ion concentration, cell age, and time of reaction also affect the antimicrobial activity of nanoparticles. For an increase in their activity, nanoparticles can be coated with several coating agents (Jaworski et al. 2018). Surface stabilizers, surfactants, polymers and oligonucleotides can be used as coating agents. These capping agents help to stabilize the nanoparticles against agglomeration.

Nanoparticles can either be organic (e.g., liposomes, polymeric, micelles, ferritin) or inorganic (e.g., metal nanoparticles). Both types of nanoparticles have been influential in treating several health conditions (Anselmo and Mitragotri 2016). Organic nanoparticles have been used to increase the bioavailability of drugs, enhance efficient drug delivery and improve antibacterial activity (Yetisgin et al. 2020). They have also been used in treating fungal infection (Mba and Nweze 2020) and have shown promises against viral infections [e.g., severe acute respiratory syndrome 2 (SARSCoV-2)] infection (Mba et al. 2021). Currently, available nanoparticulate antibacterial systems include liposomes, polymeric NPs, micelles, solid lipid NPs (SLNs), nanostructured lipid carriers (NLCs), nanocapsules, nanotubes, quantum dots, dendrimers, emulsions, nanogels, and vesicles. They are nano-scale drug delivery systems that offer a slow-release and the delivery of drugs to the targeted cells.

The metallic nanoparticles appear to be the most promising. They exhibit diverse activities against several multidrug resistant pathogens (Liao et al. 2019; Rasheed et al. 2017; Mba and Nweze 2020). The most widely studied metal nanoparticles are silver nanoparticles (AgNps) and gold nanoparticles (AuNps). Metallic oxide nanoparticles with proven antibacterial activities include copper oxide nanoparticles (CuONps), zinc oxide nanoparticles (ZnONps), titanium oxide nanoparticles $\left(\mathrm{TiO}_{2} \mathrm{Nps}\right)$, and magnesium oxide nanoparticles (MgONps). Others include calcium oxide nanoparticles (CaONps), iron oxide nanoparticles $\left(\mathrm{Fe}_{2} \mathrm{O}_{3} \mathrm{NPS}\right)$ and manganese oxide $\left(\mathrm{MnO}_{2} \mathrm{Nps}\right)$. AgNps is the most studied and most widely used among all the nanoparticles (Mohler et al. 2018). Nanoparticles can also be combined with antibiotics and other nanomaterials for improved antibacterial activity.

Moreover, the light-responsive technique specifically has been used in the development of drugs. It has also found application in the design of drug carrier systems. The lightresponsive structure can easily be regulated, and it has low invasiveness (Thang et al. 2019). Its mechanism of activity is based on the alteration of the light-sensitive molecules when stimulated by light, thus enabling the release of the encapsulated or conjugated drug (Linsley and Wu 2017). Over the years, the use of nanomaterials in photothermal therapy has received considerable attention. Several organic and polymeric nanoparticles have been reported to exhibit inherent photothermal ability (Zhao et al. 2018).
Therefore, in the face of increasing resistance to frontline antimicrobial agents and the rise in infections mostly caused by multidrug-resistant organisms, researchers have made efforts to develop alternative therapeutic approaches. The application of nanotechnology appears to be a viable solution due to the distinctive properties of nanomaterials. This review provides an important update on the issue of antimicrobial resistance. Based on recent literature, the mechanism of antimicrobial activity displayed by nanoparticles are discussed. Recent investigations reporting the activity of nanoparticles against drug-resistant bacteria are also highlighted. Moreover, insight on the synergistic activity of nanoparticles with antibiotics and other nanomaterials are also discussed extensively. Also, nanomaterials that can respond to light stimuli (photothermal therapy) to kill microbes and facilitate enhanced drug delivery and release are discussed. Finally, the recently emerging adaptive response tactics of bacteria to nanoparticles and current challenges in the use of nanoparticles as well as their future prospects are also presented.

\section{The burden of antibiotic resistance and the need for antibacterial nanomaterials}

The response of microbes to antimicrobial attack is an important illustration of adaptation and the pinnacle of evolution. Studies have shown that microbial infection is responsible for about 3 million deaths in developing countries annually. It also causes about 10 million deaths annually, mostly in the tropical countries (Dye 2014; Global Health Estimate 2016; Fenollar and Mediannikov 2018) despite the vast advances in diagnoses and therapeutics that have been achieved over the years. Developed countries are not spared either. Antimicrobial drug resistance has become a major global public health issue in medicine. In the US alone, the estimated economic burden associated with multidrug-resistant (MDR) microbes is about $\$ 20$ billion dollars yearly (Munita and Arias 2016). The issue of resistance often leaves clinicians with no reliable alternative to manage infected patients. Also, the emergence of multidrug resistant bacteria and super bacteria (bacteria resistant to almost all antibiotics) has compounded the problem. This is broadly associated with the excessive use of antibiotics which subsequently facilitates the generation and evolution of strains with genotypic and phenotypic diversities (Wang et al. 2017a, b).

Therefore, emergence of MDR and extensively-drug resistant (XDR) bacteria persist as a critical challenge in public health as it is associated with high mortality, morbidity, and high cost of treatment (Sanchez et al. 2013; Roca et al. 2015). This is further exacerbated by the ability of several bacterial strains to form biofilms, which is associated with about $65-80 \%$ of human infections (Lebeaux et al. 
2013). Cells in biofilms are usually 100-1000 times less susceptible to antibiotics than planktonic cells (Saginur et al. 2006). The increase in resistance of drugs by biofilms is due to several factors: decrease in drug penetration across the extracellular matrix, reduction in drug concentration, reduction in metabolic rates of bacteria, and transfer of resistant genes (Hall-Stoodley et al. 2004; Hall and Mah 2017). MDR $S$. aureus and $P$. aeruginos $a$ are the leading causes of chronic biofilm-associated infections worldwide, often characterized by a slower rate of wound healing, failure of catheters, and prolonged hospital stays (Nathwani et al. 2014; Sanchez et al. 2013).

Furthermore, antimicrobial drug resistance is among the three most important global public health threats identified in the twenty-first century by the World Health Organization (WHO). The ESKAPE group (Enterococcus, Staphylococcus, Klebsiella, Actinobacter, Pseudomonas, Enterobacter) are the most critical and have raised the most concerns. They are all associated with a high mortality rate. Based on reports from WHO, about $80 \%$ of the MDR or XDR microbes are due to misuse and overuse of antibiotics, and these infections are associated with severe adverse effects. Currently, there are limited therapeutic and prevention options due to the expansion of MDR bacteria and other resistant pathogens. There is a need for alternative therapeutic options for microbial pathogens. The failure of most antibiotics necessitates the search for better treatment options. Also, for effective infection control, drugs that can treat infection with the smallest possible dose is an appropriate approach (Morgan et al. 2011; WHO 2015).

Nanotechnology is a promising therapeutic strategy due to its high efficacy and therapeutic index against microbes (Hussain et al. 2018). Nanoparticles offer a viable alternative in the management of most bacterial infections, especially those involving multi-drug resistant organisms. Nanoparticles can be used singly or combined with antibiotics providing excellent synergistic effects. Nanomaterials that can respond to diverse endogenous and exogenous stimuli to killed microbes and also facilitate enhanced drug deliver and release are promising strategies (Hsiao et al. 2015; Qiu et al. 2018).

\section{Metallic and metal oxide nanoparticles are promising antibacterial agents}

AgNps are currently seen as the next generation antibiotics. This is because of their high effectiveness in inhibiting microorganisms. Currently, AgNps are the leading nanoparticles among all the commercialized nanomaterials (Arya et al. 2019). Research into their use as antimicrobial agents has intensified over the years due to their reduced toxicity when compared to other nanoparticles. Attachment and penetration of the AgNps nanoparticles to microbial membrane surface is usually the first step in its cytotoxic mechanism (Singh et al. 2015). The damage to internal components is caused by the released $\mathrm{Ag}^{+}$ions which trigger the generation of ROS and subsequent oxidative stress induction which affect the $\mathrm{Na}^{+} / \mathrm{K}^{+}$ATPase pump and signal transduction pathways (Singh et al. 2015; Flores-Lopez et al. 2019). $\mathrm{Ag}^{+}$ions and $\mathrm{AgNps}$ also interact with DNA (phosphoruscontaining compounds) leading to protein inactivation and subsequent cell death. In fact, sulphur, chlorine, thiols, and oxygen can interact with a great effect on $\mathrm{Ag}^{+}$ion release (Maurer and Meyer 2016).

Also, the rate at which this $\mathrm{Ag}+$ ion is released is largely affected by the size (Sriram et al. 2012; Abuayyash et al. 2018). Small size AgNps can easily penetrate the cell wall. They also alter the structural integrity and membrane architecture causing an increase in permeability and subsequent cell apoptosis. The type of bacterial species also influences AgNps activity. This is because of the different cell wall composition, thickness, and arrangement (Tamayo et al. 2014). The precise antimicrobial activity of AgNps beside the generation of ROS is associated with the cell wall and plasma membrane damage according to Hamouda et al. (2019). This is because of protein inactivation and membrane lipid peroxidation. These activities modify the structural membrane integrity leading to the disorder of the transport proteins. It also causes potassium leakage.

AuNps are among the most widely researched nanoparticles with good antimicrobial activity (Shamaila et al. 2016; Tao 2018; Bilal et al. 2017). AuNps exhibit several shapes including triangular, spherical, hexagonal, and even rod-like shapes (Abdel-Raouf et al. 2017). The triangularshaped AuNps as previously reported by Smitha and Gopchandran (2013) exhibit strong antibacterial activity against several bacteria compared to spherically-shaped AuNps. AuNps adhere to the membrane via electrostatic interaction and disrupt membrane integrity (Kundu 2017). They can cause leakage of intracellular components by generating holes in the membrane. AuNps can bind to DNA inhibiting replication and transcription. They can also aggregate with biofilm formed by microbes. Interactions between AuNps also provoked the formation of ROS essential for cell death. They alter membrane potential and decrease ATP synthase activities thereby reducing several metabolic activities. AuNps just like AgNps disrupt cell membrane integrity and structure (Rattanata et al. 2016). AuNps prevent rRNA from binding to its subunits, thus preventing translation (Cui et al. 2012). AuNps also interact with sulphur or phosphorus-containing nucleotides. AuNps supplemented with antibiotics usually shows strong antibacterial activity. According to a study by Brown et al. (2012), ampicillin integrated with AuNp was strongly effective against bacteria (P. aeruginosa, E. coli, Enterobacter aerogenes and MRSA) resistant to 
ampicillin. The AuNp-AMP complex disrupts and inhibits the transmembrane pump catalyzing drug efflux. The AuNpAMP also overwhelmingly neutralizes the high $\beta$-lactamase expressed by the bacteria.

Furthermore, copper/copper oxide nanoparticles (CuNps/ CuONps) exhibit antimicrobial activity (El-Batal et al. 2017; Asemani and Anarjan 2019). Available report suggests that its antimicrobial activity is derived via the electrostatic attraction between the nanoparticle and the cell (Bogdanovic et al. 2014). The $\mathrm{Cu}^{2+}$ ion can also bypass the lipid bilayer and gain access into the cell. Upon penetration into the cell, it triggers the production of ROS. Lipid peroxidation and protein oxidation is also evident (DeAlba-Montero et al. 2017). The ability of $\mathrm{Cu}$ to alternate between +1 and +2 oxidation state is also responsible for its antimicrobial activity. A recent investigation reported that $\mathrm{CuONps}$ can interact with amino acids with a great influence on its bacterial activity (Badetti et al. 2019).

$\mathrm{ZnO}$ nanoparticle is also a promising antibacterial agent (Bhuyan et al. 2015). It was previously reported that surface coating of $\mathrm{ZnONps}$ could prevent their interactions with biological fluid. However, Pranjali et al. (2019) found that PEGylated ZnONps strongly bind and interact with peritoneal dialysis (PD) fluid, lactic and citric acids leading to agglomeration. In addition, a drastic decrease in the bacterial inhibition effect was observed for both the $\mathrm{ZnONps}$ and the PEG-coated $\mathrm{ZnONps}$ dispersed in biological fluid. ZnONps release $\mathrm{Zn}^{2+}$ ions when in contact with the microbial cell. The $\mathrm{Zn}^{2+}$ ions disrupt the cell membrane. The interaction between the ions and several intracellular components further causes more harm to the cell (Li et al. 2011). In addition, $\mathrm{Zn}^{2+}$ causes the generation of ROS (Kumar et al. 2011; Singh et al. 2020). Recently, Nejabatdoust et al. (2019) reported that $\mathrm{ZnONPs}$ conjugated with thiosemicarbzide and functionalized by glutamic acid modifies the expression of efflux pump genes in multiple drug-resistant $S$. aureus.

$\mathrm{TiO}_{2} \mathrm{~Np}$ produces ROS which is responsible for cell membrane damage and disruption of oxidative phosphorylation (Singh et al. 2018). $\mathrm{TiO}_{2} \mathrm{~Np}$ also inactivates signaling pathways, reduces the co-enzyme-independent respiratory network as well as the take-up and transport of Fe and P. It also decreases the biosynthesis and degradation of heme group (Foster et al. 2011). Its activity is also photo dependent. The generation of free radicals has also been reported (Wu et al. 2010). Evidence is also available that it can damage the peptidoglycan, lipopolysaccharide, in addition to the phospholipid bilayer (Liu et al. 2010). Similarly, MgONp can produce ROS that is highly detrimental to cells (Krishnamoorthy et al. 2012; He et al. 2016). Nguyen et al. (2018) reported that $\mathrm{MgONps}$ reduce biofilm forming ability of $S$. epidermidis and damages the membrane of $E$. coli causing cell apoptosis. The authors suggested that the production of ROS, $\mathrm{Ca}^{2+}$ concentrations and quorum sensing are the mechanisms contributing to their antimicrobial activity. In addition, the $\mathrm{MgONp}$ cell surface attachment damages membrane integrity and cause leakage of intracellular components. In a recent study, $\mathrm{MgONps}$ and $\mathrm{MnONps}$ were biosynthesized using Matricaria chamomilla $\mathrm{L}$ extract. The results showed that the nanoparticles invade the cells and damage the membrane. This led to the leakage of intracellular cytoplasmic content (Ogungemi et al. 2019). According to Ogungemi et al. (2019) MgONp antimicrobial activity is also achieved by the production of $\mathrm{Mg}^{2+}$ ion, cell membrane interaction and $\mathrm{pH}$ changes.

Also, a recent study showed that $\mathrm{Fe}_{3} \mathrm{O}_{4} \mathrm{Nps}$ reduce $\mathrm{H}^{+}$-flux through bacterial membrane. $\mathrm{Fe}_{3} \mathrm{O}_{4} \mathrm{Nps}$ specifically inhibit ATP-associated metabolism. There was also a decrease in membranes associated $\mathrm{H}_{2}$ production (Gabrielyan et al. 2019). Several researchers have investigated the antimicrobial activity of biosynthesized FeNps and $\mathrm{Fe}_{2} \mathrm{O}_{3} \mathrm{Nps}$ (Sathishkumar et al. 2018; Jagathesan and Rajiv 2018; Madivoli et al. 2019). Studies are also available reporting the antimicrobial potentials of calcium oxide nanparticles (Butt et al. 2015; Balaganesh et al. 2018; Pasupathy and Rajamanickam 2019; Gurav et al. 2020). Figure 1 summarizes the mechanisms of antibacterial activity of nanoparticles while Table 1 shows the recent studies reporting the antimicrobial activity of nanoparticles.

\section{Synergistic antimicrobial activity of nanoparticles}

The activities of nanoparticles can be greatly enhanced when conjugated or coated with other materials. In fact, combining nanoparticles with antibiotics can help reduce microbial resistance. In resistant strains, variation in the mode of action of antibiotics and the nanoparticles enhance the susceptibility of the microbe. If a particular strain is resistant to one antimicrobial agent, another antimicrobial agent could trigger the killing by using a different mechanism. The nanoparticles can also act as carriers of antibiotics thereby facilitating access to bacterial cell walls. The antibiotic in turn damages the cell wall enabling easy entry of the nanoparticles and its complex.

In a study that combined amoxicillin with AgNps, a significant reduction in growth of bacteria was evident $(\mathrm{Li}$ et al. 2005). The transport of amoxicillin across the microbial membrane was facilitated by the hydrophobic nature of the AgNps which interact with the cell membrane. Duran et al. (2010) showed that AgNps and amoxicillin synergistic activity was due to sulfur bridge formation between the two agents. Fayaz et al. (2010) showed that AgNps-ampicillin complex inhibits the formation of crosslinks in the peptidoglycan layer leading to cell death. This complex also prevented the unwinding of DNA. It was reported 


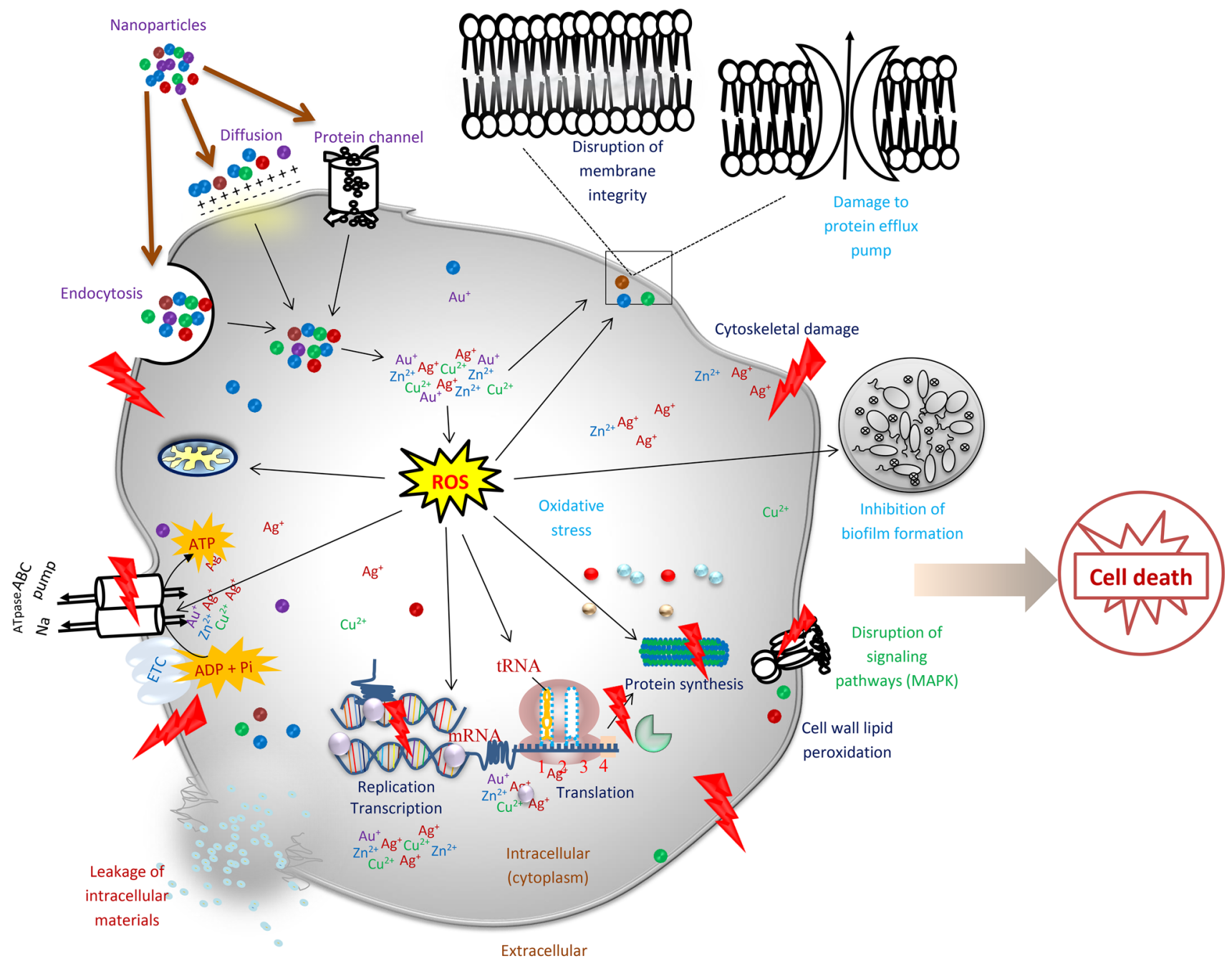

Fig. 1 Mechanism of nanoparticles activity against bacteria

by Panacek et al. (2015) that a very low concentration of $\mathrm{AgNps}$ is needed for synergistic activity with antibiotics with no cytotoxic effect. Wan et al. (2016) showed the synergistic activity of AgNps combined with polymyxin B and rifampicin against $A$. baumannii. It was also reported by Banoee et al. (2010) that ZnONps-ciprofloxacin complex interrupts with the endogenous efflux transporter (NorA) and the Omf proteins which facilitate the entrance of ciprofloxacin into the cell. The synergistic activity of $\mathrm{TiO}_{2} \mathrm{Nps}$ and several antibiotics against MRSA was also studied by Roy et al. (2010). Significant antibacterial activity was observed. However, the exact mechanism of its synergistic activity is yet to be elucidated. Chamundeeswari et al. (2010) reported that AgNps-ampicillin complex exhibit greater antimicrobial activity against $S$. aureus, E. coli and $K$. mobilis than single amoxicillin.

In a more recent investigation, Farzana et al. (2017) reported the antimicrobial behavior of $\mathrm{ZnONps}$ and $\beta$-lactam antibiotics against bacteria. AuNps-antibiotics complex also exhibited excellent antimicrobial activity (Shaikh et al. 2019). Mohamed (2020) reported that AuNps conjugated with ampicillin/amoxicillin showed significant antibacterial activity and was biocompatible with treated cells. Farooq et al. (2019) showed that rifampicin conjugated AgNps produced anti-biofilm activity against MRSA and K. pneumonia. Surwade et al. (2019) reported that AgNps combined with ampicillin showed very strong synergistic effects against MRSA. A similar result was provided by Sajjad et al. (2019) who studied the synergistic activity of $\mathrm{AgO}_{2} \mathrm{Nps}$ and ceftriaxone against E. coli. Several other researchers have reported the synergistic effects of nanoparticles with antibiotics (Shahbazi et al. 2019; Gounani et al. 2018). Table 2 summarizes other studies that reported the synergistic activity of nanoparticles with antibiotics. Moreover, nanoparticles conjugated with specific antibody exhibit excellent activity against resistant pathogens. Al-Sharqi et al. 


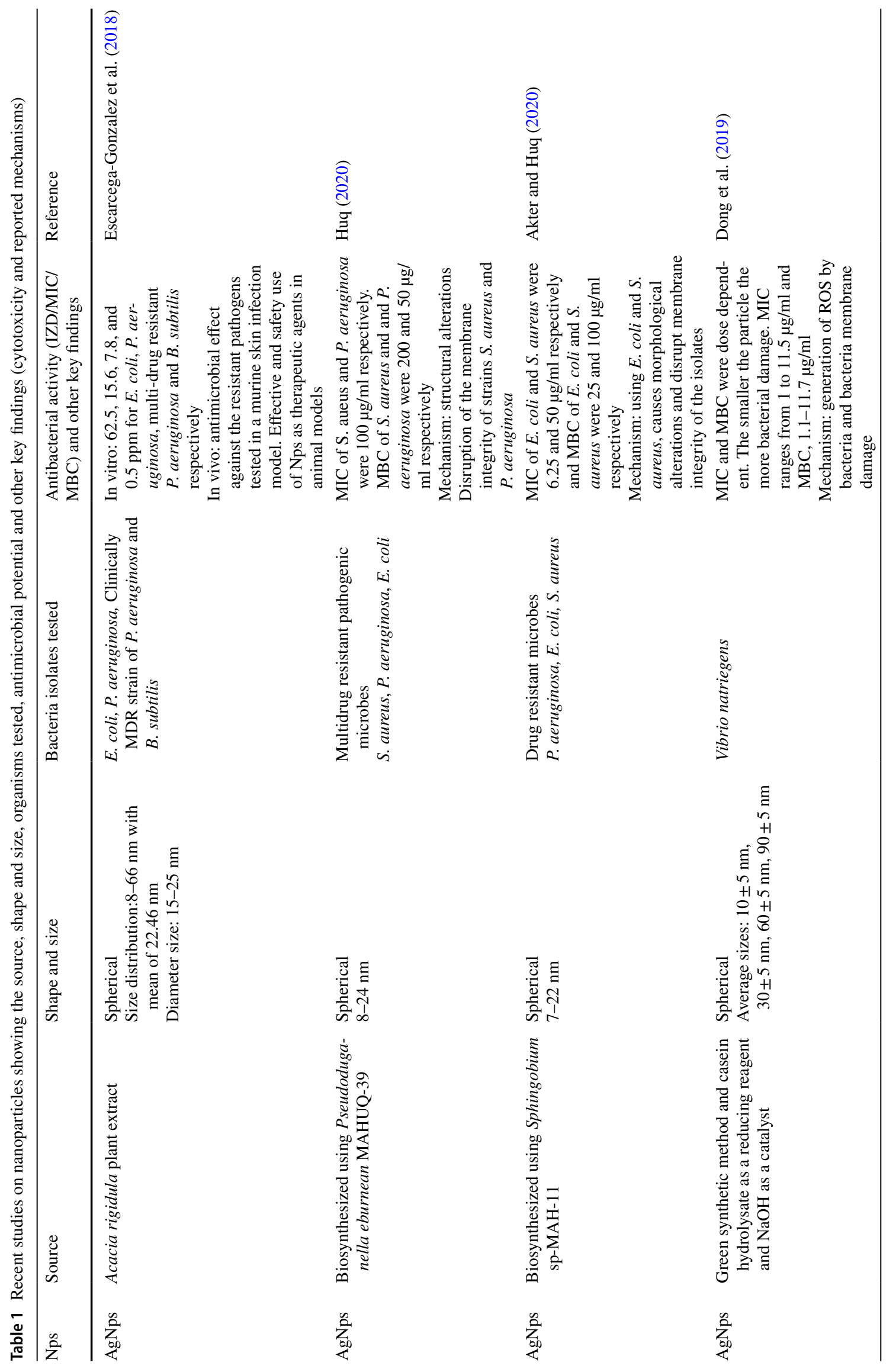




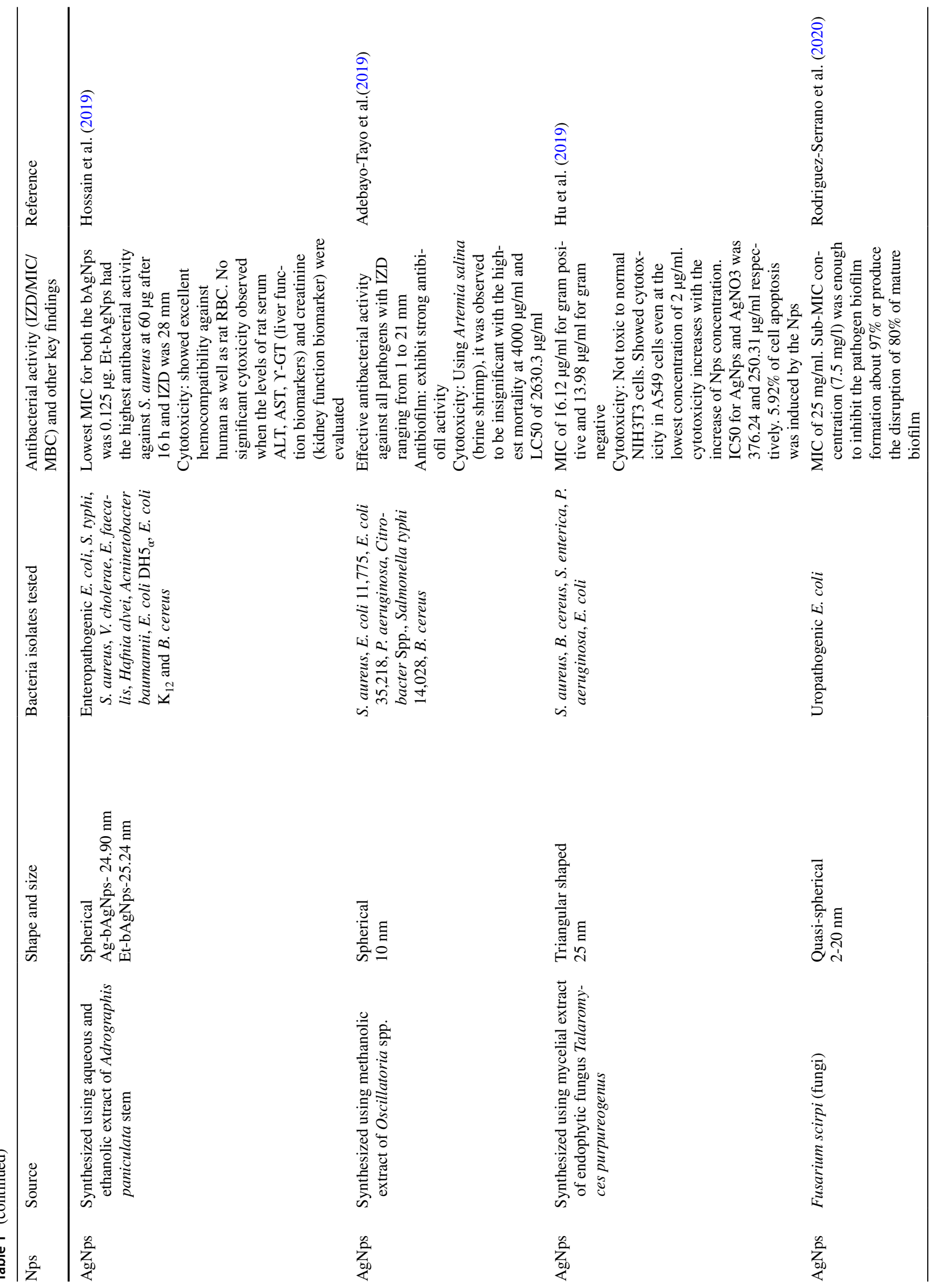




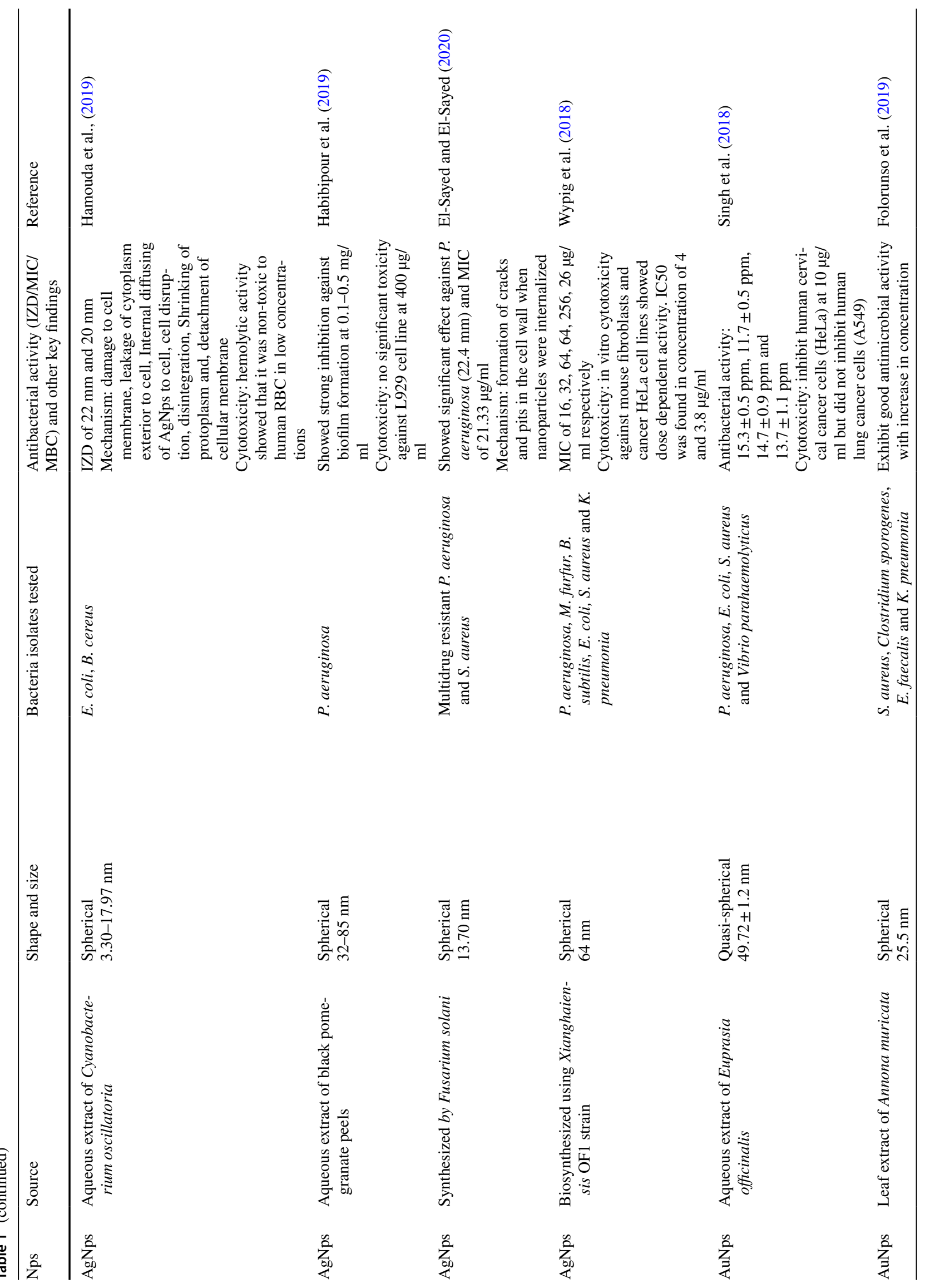




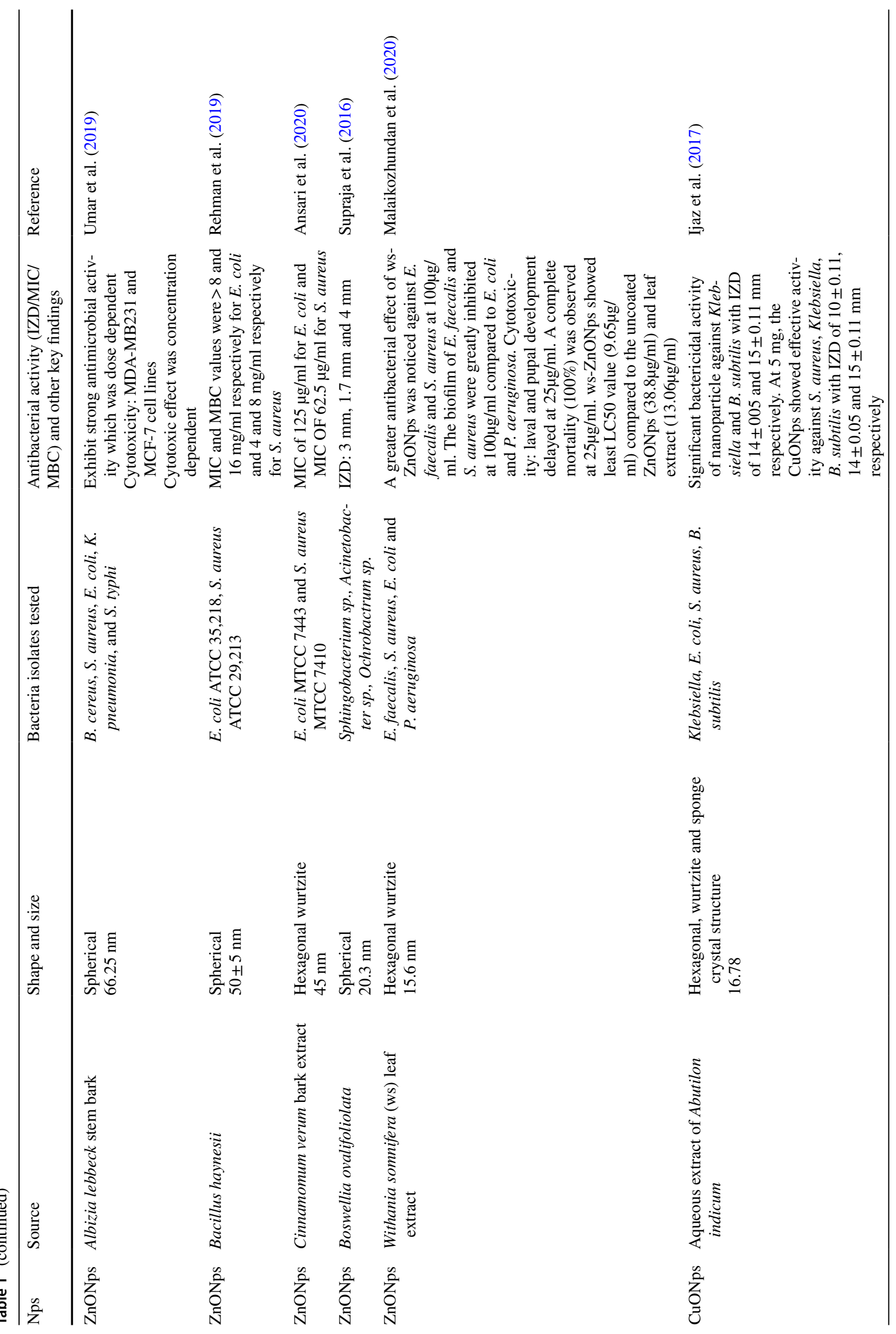




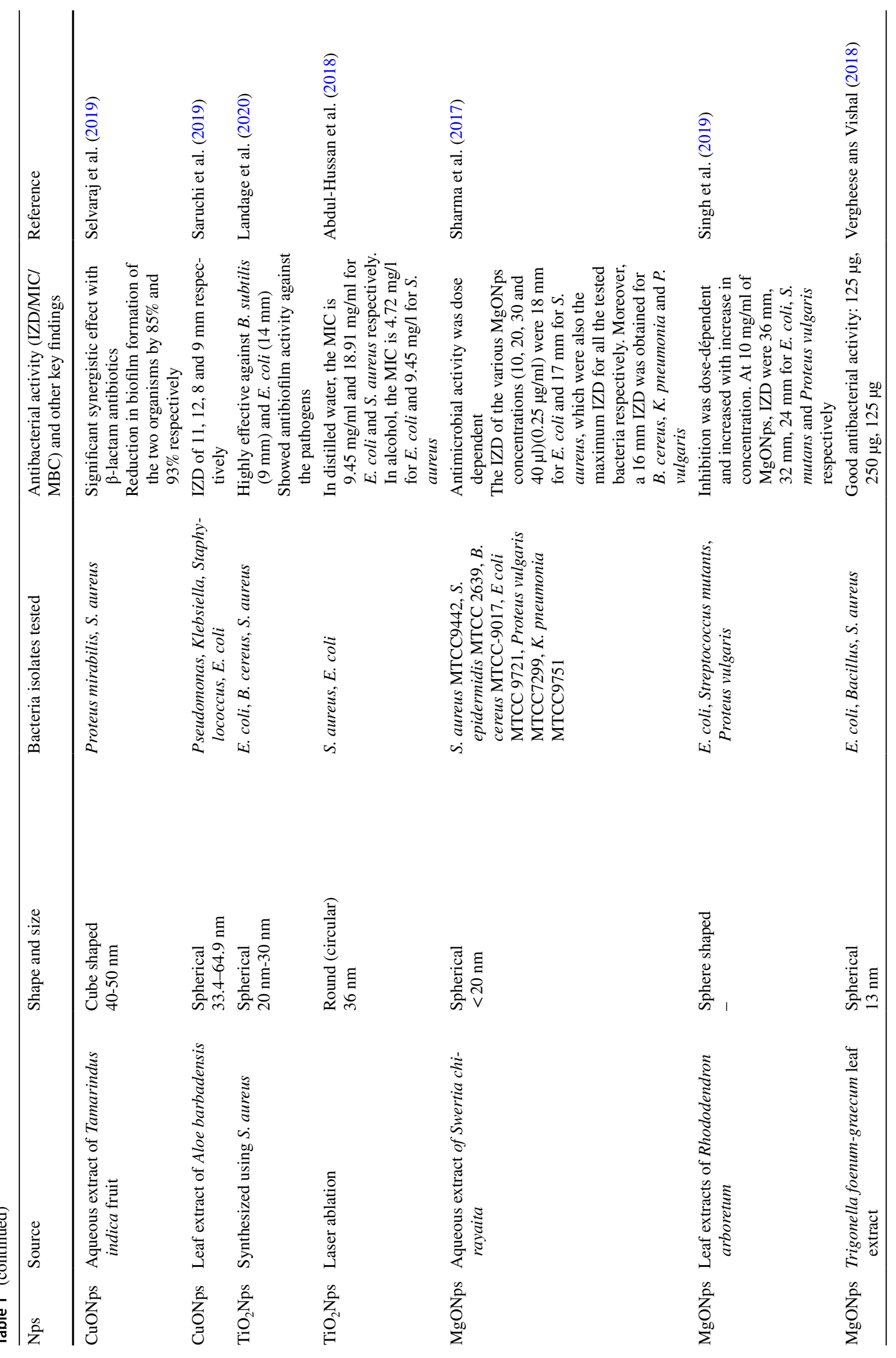




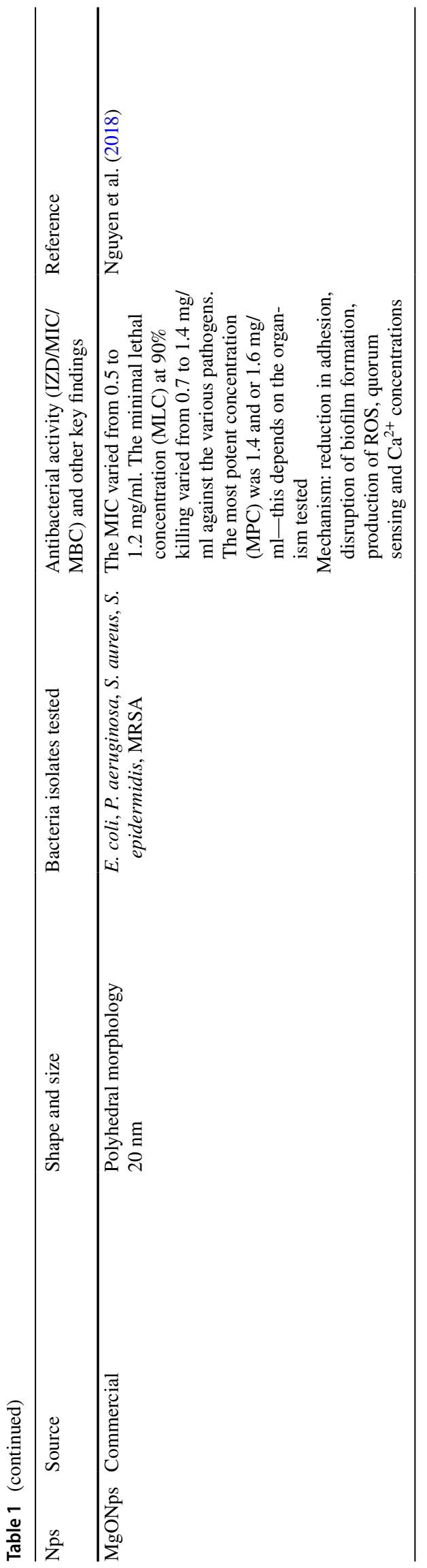

(2019) reported that AgNps conjugated with specific antibody showed good antimicrobial activity against $S$. aureus.

While nanoparticle-antibiotic complex provides a strong synergism against pathogenic microbes, the combination of two different nanoparticles can help improve their activity while reducing their toxicity. Coating nanoparticles with biomaterials can also enhance their activity. Coating AgNps with $\mathrm{TiO}_{2}$ or other metal or metallic oxide materials enhances its antimicrobial activity. Hu et al. (2017) showed that $\mathrm{ZnO} / \mathrm{Ag}$ bimetallic nanoflowers exhibit improved antibacterial activity. Recent studies by Jaworski et al. (2018) and Cobos et al. (2020) showed that AgNps decorated with graphene oxide nanocomposites exhibit strong antibacterial activity. Nunez et al. (2019) also showed that nanohybrids mediated AgNps was effective against Gram positive and Gram-negative microbes (Nunez et al. 2019). Table 3 summarizes some recent studies on nanocomposites/ nanohybrids.

\section{Photothermal therapy using nanomaterials is a promising approach to combat antimicrobial resistance}

Over the years, the use of nanomaterials in photo thermal therapy has received considerable attention (Wei et al. 2018; Canaparo et al. 2019; Ramezani et al. 2020). The light-responsive technique specifically has been used in the development of drugs. It has also found application in the design of drug carrier systems and as an antibacterial agent (Qi et al. 2019). The light-responsive structure can be easily regulated and it has low invasiveness (Bao et al. 2016). Its mechanism of activity is based on the alteration of the lightsensitive molecules when stimulated by light, thus enabling the release of the encapsulated or conjugated drug (Chen and Zhao 2018).

For the treatment of cancer, photothermal therapy uses the thermal stress caused by irradiation of light of a specific wavelength (Cheng et al. 2014a). They have also been used for the delivery of anticancer drugs (Yu et al. 2020). Although photothermal therapy has found application in the treatment of cancer, it is effective at killing pathogens irrespective of their drug resistance level or their metabolic state within the biofilm (Galanzha et al. 2012). Halstead et al. (2016) showed that blue light has a broad-spectrum antimicrobial activity against all six ESKAPE members. Further investigations also showed that low penetrating blue light of about $415 \pm 10 \mathrm{~nm}$ is preferable for the treatment of wound infections as it is associated with low damage to the tissue cells (Wang et al. 2017a, b; Katayama et al. 2018). There was an inhibitory effect on bacterial growth in a study that exposed $P$. aeruginosa to light-emitting diode (LED) (Sueoka et al. 2018). The increase in antimicrobial activity was 
Table 2 Nanoparticles combined with antibiotics for antimicrobial activity

\begin{tabular}{|c|c|c|c|c|}
\hline Nanoparticles & Synthesis & Antibiotics & Organisms tested/Activity & Reference \\
\hline AuNps & - & Ampicillin & $\begin{array}{l}2 \text { strains of } S \text {. aureus } \\
\text { MRSA } \\
\text { Significant antibacterial activ- } \\
\text { ity, cytocompatible against } \\
\text { human dermal fibroblasts }\end{array}$ & Fan et al. (2019) \\
\hline CuNps & Green synthesis & $\begin{array}{l}\text { Erythromycin } \\
\text { Azithromycin } \\
\text { Norfloxacin }\end{array}$ & $\begin{array}{l}\text { Klebsiella, Pseudomonas, } \\
\text { E. coli, Shigella } \\
\text { Staphylococcus } \\
\text { At } 50,100,200,400 \mu \mathrm{g} / \mathrm{ml}, \\
\text { all bacteria were resistant to } \\
\text { antibiotics }\end{array}$ & Kaur et al. (2019) \\
\hline $\mathrm{AgNps}$ & $\begin{array}{l}\text { Synthesized using corn leaf } \\
\text { waste of zea mays extract }\end{array}$ & $\begin{array}{l}\text { Kenamycin } \\
\text { Rifampicin }\end{array}$ & $\begin{array}{l}\text { Bacillus cereus, E. coli, } S . \\
\text { aureus, L. monocytogenes, } \\
\text { S. typhimurium }\end{array}$ & Patra and Baek (2017) \\
\hline $\mathrm{AgNps}$ & $\begin{array}{l}\text { Synthesized using Adiantum } \\
\text { philippense extract }\end{array}$ & Amoxicillin & MRSA & Kalita et al. (2016) \\
\hline $\mathrm{AgNps}$ & $\begin{array}{l}\text { Leaf extract of Cassia rox- } \\
\text { burghii }\end{array}$ & $\begin{array}{l}\text { Ampicillin, Polymyxin, } \\
\text { Clotrimazole } \\
\text { Amikacin, Chloramphenicol, } \\
\text { Penicillin-G, Tetracycline, } \\
\text { Amoxiclav, Cefpirome } \\
\text { Gentamycin, clotrimazole }\end{array}$ & $\begin{array}{l}\text { S. aureus, B. subtilis, E. coli, } \\
\text { P. aeruginosa }\end{array}$ & Moteriya et al. (2017) \\
\hline AgNps & $\begin{array}{l}\text { Spherical shaped Nps } \\
8.57 \pm 1.17 \mathrm{~nm}\end{array}$ & Ampicillin, Amikacin & $\begin{array}{l}\text { E. faecium, } S \text {. aureus, } A \text {. bau- } \\
\text { mannii,, Enterobacter cloa- } \\
\text { cae, E. coli, K. pneumonia } \\
\text { Morganella morganii, } P \text {. } \\
\text { aeruginosa } \\
\text { Excellent antimicrobial } \\
\text { activity }\end{array}$ & Lopez-Carrizales et al. (2018) \\
\hline CuNps & $\begin{array}{l}\text { Synthesized using Camel- } \\
\text { lia sinensis (green tea) and } \\
\beta \text {-cyclodextrin }\end{array}$ & $\begin{array}{l}\text { Penicillin, Streptomycin, } \\
\text { Ampicillin } \\
\text { Amoxicillin, Gentamicin, } \\
\text { Ciprofloxacin }\end{array}$ & $\begin{array}{l}\text { S. pyrogenes, E. coli, S. typhi, } \\
\text { Micrococcus lutus } \\
\text { Streptococcus mutans }\end{array}$ & Mandava et al. (2017) \\
\hline $\begin{array}{l}\text { Bimetallic } \\
\text { Ag-Au nano- } \\
\text { particle }\end{array}$ & $\begin{array}{l}\text { Synthesized using cell free } \\
\text { supernatant of P. veronii } \\
\text { strain AS41G on Annona } \\
\text { squamosal L }\end{array}$ & $\begin{array}{l}\text { Kanamycin, Bacitracin, Gen- } \\
\text { tamycin } \\
\text { Streptomycin,Erythromycin, } \\
\text { Chloramphenicol }\end{array}$ & $\begin{array}{l}\text { E. coli, B. subtilis, K. pneumo- } \\
\text { niae }\end{array}$ & Sharma et al. (2017) \\
\hline $\mathrm{ZnONps}$ & - & $\begin{array}{l}\text { Ciprofloxacin } \\
\text { Ampicillin }\end{array}$ & $\begin{array}{l}\text { E. coli (MTCC 739), Kleb- } \\
\text { siella pneumonia (MTCC } \\
\text { 109), P. aeruginosa (MTCC } \\
\text { 741), Salmonella typhi } \\
\text { (MTCC 98), S. aureus } \\
\text { (MTCC 737), B. subtilis } \\
\text { (MTCC 736) } \\
\text { Synergistic effects observed } \\
\text { No antagonistic effect } \\
\text { observed }\end{array}$ & Sharma and Jandaik (2016) \\
\hline $\mathrm{ZnONps}$ & - & $\begin{array}{l}\text { Ciprofloxacin } \\
\text { Ceftazidime }\end{array}$ & $\begin{array}{l}\text { A. Baumannii } \\
\text { Combination caused increased } \\
\text { uptake of antibiotic } \\
\text { It changes the cells from rod } \\
\text { to cocci form }\end{array}$ & Ghasemi and Halal (2016) \\
\hline
\end{tabular}


Table 2 (continued)

\begin{tabular}{|c|c|c|c|c|}
\hline Nanoparticles & Synthesis & Antibiotics & Organisms tested/Activity & Reference \\
\hline $\mathrm{AgNps}$ & - & $\begin{array}{l}\text { B-lactam (ampicillin and } \\
\text { penicillin) } \\
\text { Quinolone (enoxacin) } \\
\text { Aminoglycoside (kenamycin } \\
\text { and neomycin) } \\
\text { Polypeptide (tetracycline) }\end{array}$ & $\begin{array}{l}\text { Salmonella typhimurium } \\
\text { DT104 } \\
\text { Kenamycin, Enoxacin, } \\
\text { neomycin and tetracycline } \\
\text { exhibited synergistic activ- } \\
\text { ity against the pathogen. } \\
\text { Ampicillin and penicillin } \\
\text { do not show any synergistic } \\
\text { activity } \\
\text { AgNps form complex } \\
\text { with antibiotics (AgNps- } \\
\text { tetracycline). The AgNps- } \\
\text { tetracycline interact strongly } \\
\text { with Salmonella causing } \\
\text { Ag }{ }^{+} \text {release. The increase } \\
\text { in Ag + concentration in the } \\
\text { cell wall facilitate bacte- } \\
\text { rial growth inhibition and } \\
\text { subsequent death }\end{array}$ & Deng et al. (2016) \\
\hline
\end{tabular}

possible because the bacteria that withstand the initial PDT were subsequently affected by singlet oxygen produced due to the excitation of the remaining PS. Photothermal therapy leverage the plasmon resonance features of metals, especially AuNps. There is usually the absorption of energy in the visible light spectrum and the omission of energy as heat energy to the immediate medium (Jain et al. 2007; Mocan et al. 2014).

Several organic and polymeric nanoparticles have been reported to exhibit inherent photothermal ability (Zhao et al. 2018). Also, AuNps, iron oxide, black phosphorus, graphene, and many other polymeric nanoparticles with potential for photothermal conversion have been developed for antibiotic drug delivery ( $\mathrm{Ji}$ et al. 2016; Hu et al. 2013) and chemo-phothermal therapy against pathogens under irradiation by NIR (Hu et al. 2013; Chiang et al. 2015; Meeker et al. 2016). Near-infrared (NIR) light is an excellent exogenous stimulus with promising potential against drug-resistant pathogens. The induction/activation of photothermal therapy (PTT) by NIR enables the PTT to enter deep into the tissue with little cytotoxicity. PTT can disrupt membrane permeability and signaling cascade of pathogenic organisms, disrupt key enzymes and proteins, and cause cell death (Ray et al. 2012; Kim et al. 2015; Korupalli et al. 2017). Kuang et al. (2017) demonstrated the photothermal therapeutic potential of IR-780 iodide (IR780) (a NIR fluorescence dye) encapsulated in cRGD-conjugated solid lipid nanoparticle. The low cytotoxicity, ease of been wrapped by hydrophobic carriers (inherent lipophilicity) and ease of degradation in the cell make IR780 a suitable agent for in vivo photothermal therapy (Ray et al. 2012). Also, under near-infrared (NIR) light irradiation, graphenebased nanomaterials exhibit high photothermal conversion efficiency and outstanding, amphiphilicity. This attribute enables them to attach to the cell membrane of organisms enhancing nanoscale delivery of antimicrobial agents (Yuan et al. 2018; Ran et al. 2017).

Recently, it was shown that silica-coated gold-silver nanocages (Au-Ag@SiO2 NCs) under NIR laser irradiation showed reliable increases in microbial resistance compared to $\mathrm{Au}-\mathrm{Ag}$ NCs alone (Wu et al. 2019). Coating the $\mathrm{Au}-\mathrm{Ag}$ NCs with silicon dioxide improved the surface plasmon resonance of $\mathrm{Au}-\mathrm{Ag} \mathrm{NCs}$ (Fig. 2). Also, upon irradiation of Au-Ag@SiO2 NCs with NIR laser for $10 \mathrm{~min}$, there was a swift temperature rise. Importantly, it was noticed that the increase in the concentration of Au-Ag@SiO2 NCs and the time of laser irradiation correlated with a rise in temperature. This showed that the heat produced by this nanomaterial was rapid and able to eliminate $E$. faecium, $S$. aureus, $K$. pneumoniae, A. baumannii, $P$. aeruginosa, and Enterobacter spp. (ESKAPE) pathogens.

\section{Reports on bacterial resistance to nanoparticles are gradually emerging}

Not minding the effectiveness of an antimicrobial agent, most microbes often find strategies to maneuver these agents. The flexibility of microbial genome and the selective pressure exerted by most biomaterials often facilitate the emergence of resistant. Thus, irrespective of the different mechanisms of nanoparticle activity against microbes, resistance of microbes to nanoparticles have been reported. Efflux pumps, biofilm formation/adaptation, electrostatic repulsion, alterations of morphology and mutations are some of the reported microbial resistance mechanisms to 


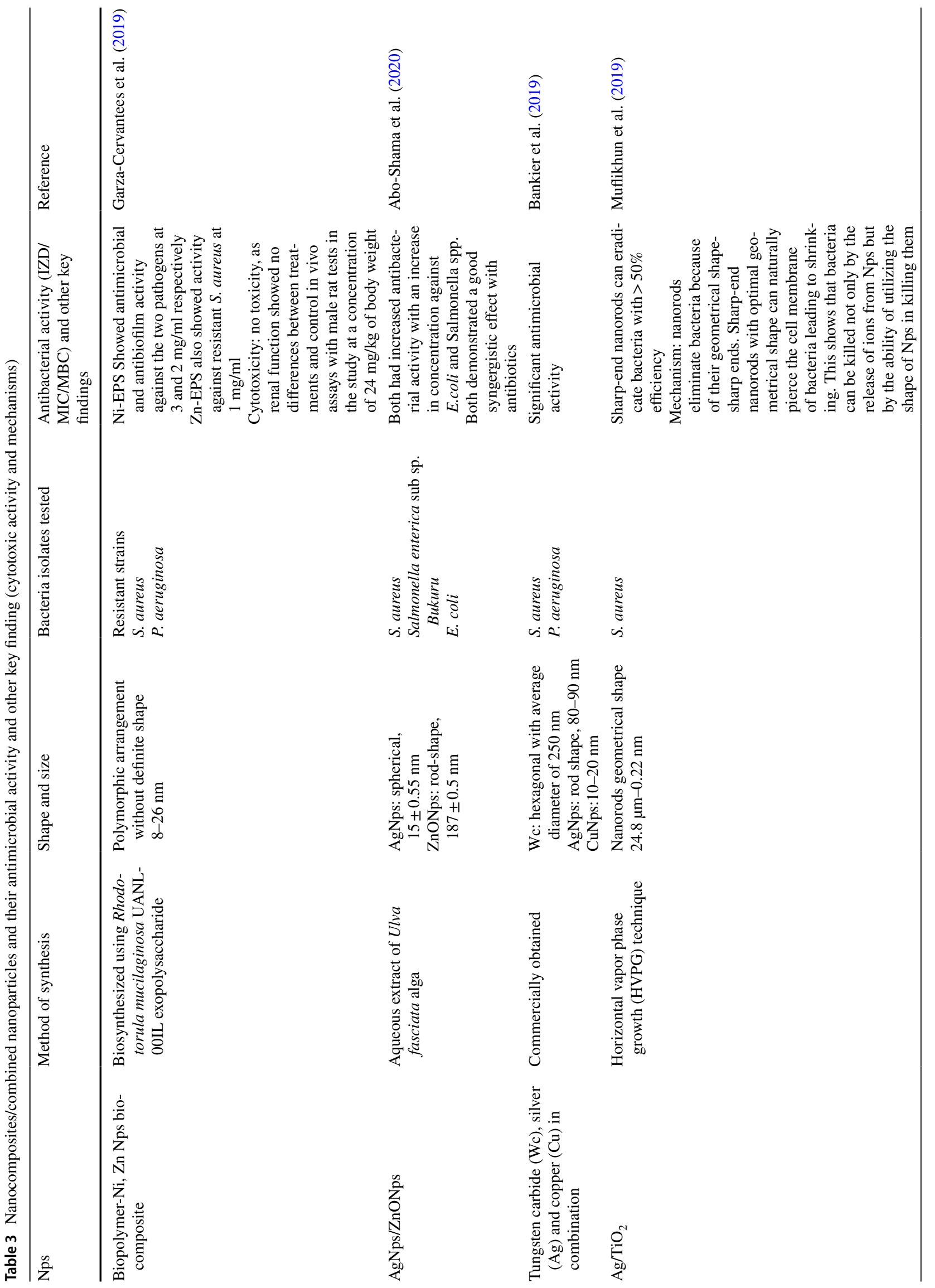




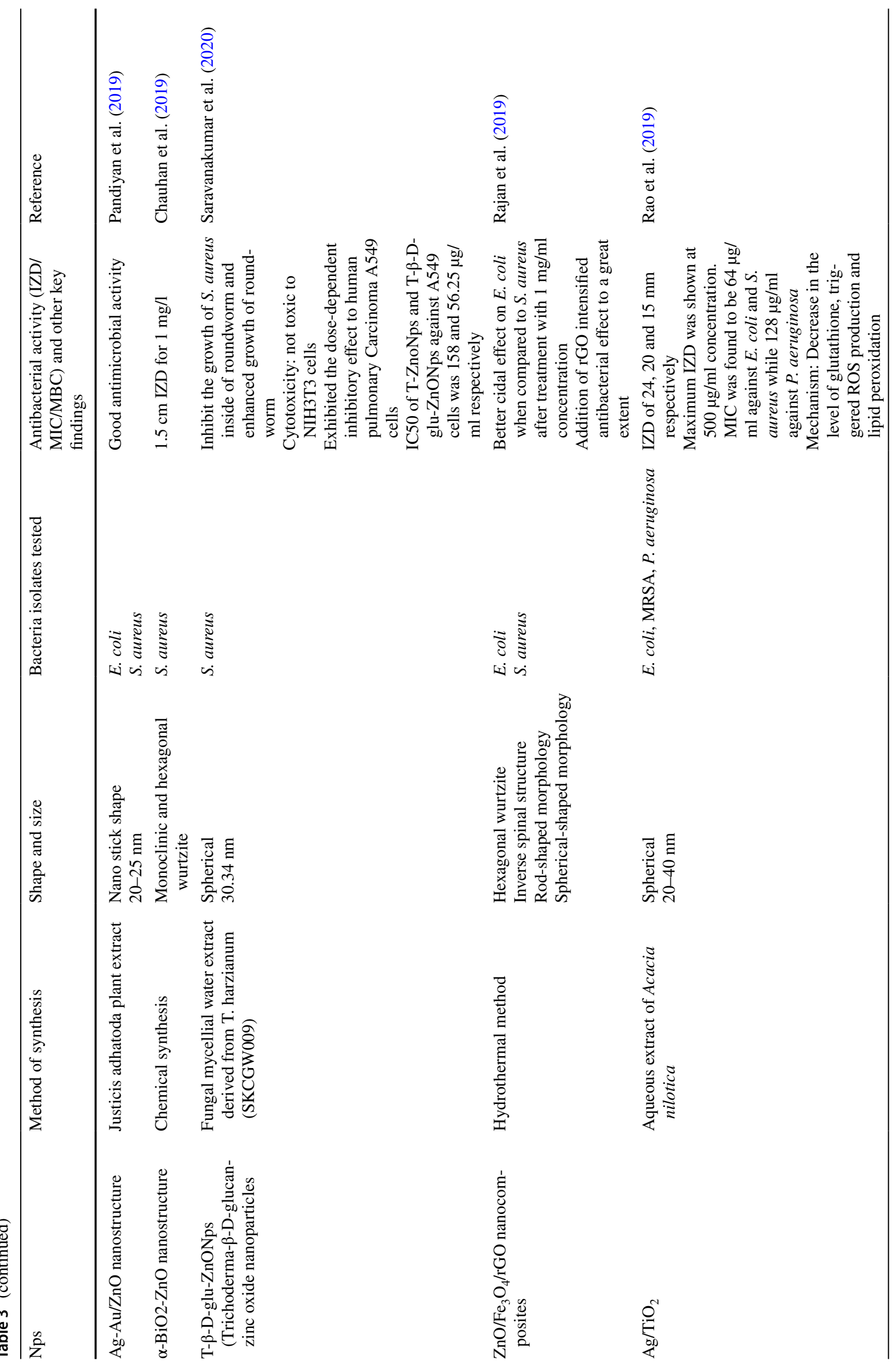


World Journal of Microbiology and Biotechnology (2021) 37:108

Page 17 of $30 \quad \mathbf{1 0 8}$

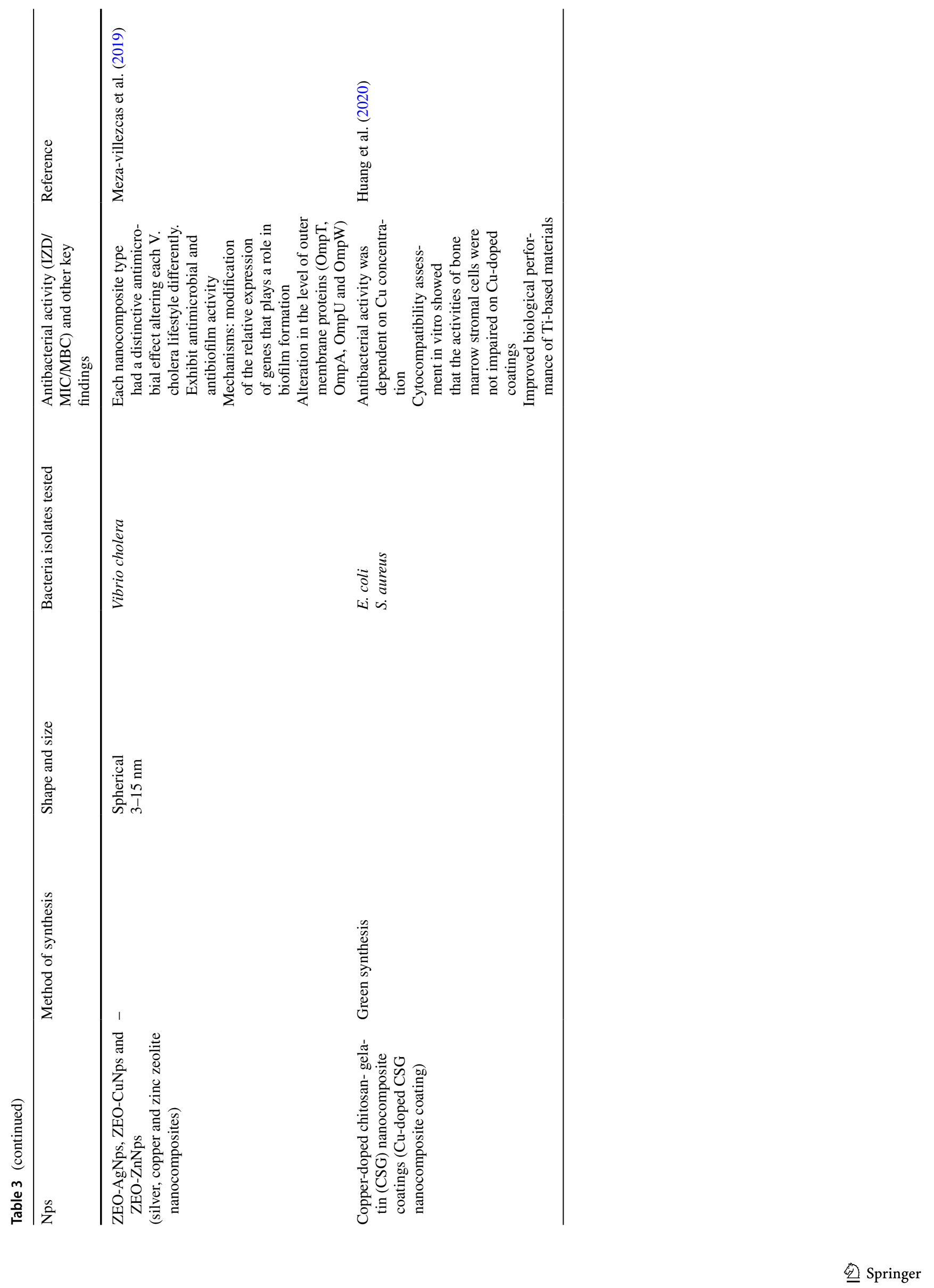


Fig. 2 Silica-coated gold-silver nanocages ( $\mathrm{Au}-\mathrm{Ag} \mathrm{NCs})$ showing antibacterial activity by a photothermal effect. Reproduced from Wu et al. (2019) with permission
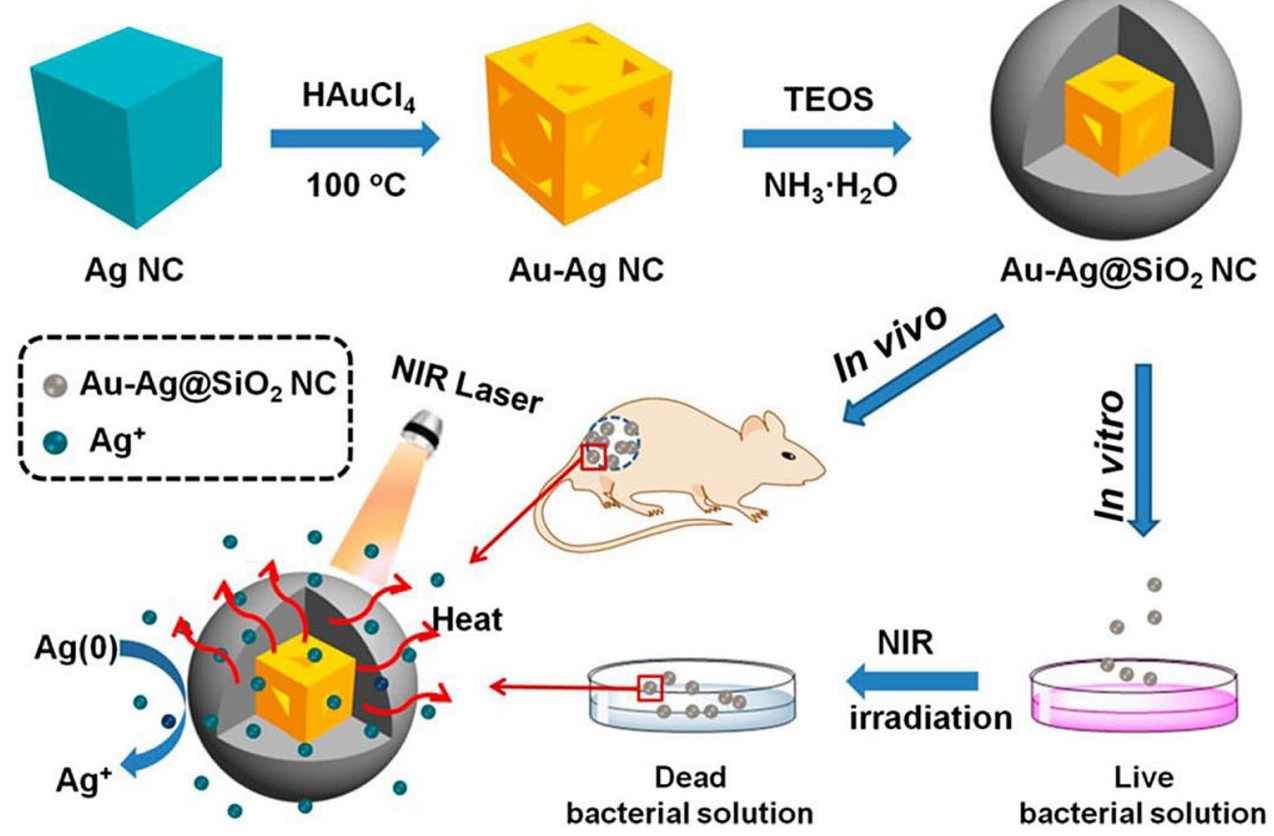

nanoparticles as reported by Nino-Martinez et al. (2019) in a review.

Previously it was shown by Li et al. (1997) that the down regulation of genes coding for the porin proteins causes a decrease in nanoparticle penetration into the cell. Jordan et al. (2008) showed that the presence of envelop stress response (ESR) mechanisms help to maintain bacterial membrane integrity, reducing their interaction with positively charged nanoparticles and alterations of lipopolysaccharide (LPS) and its constituents. In a subsequent investigation by Li et al. (2010) it was also reported that the oxidation and interaction of nanoparticles with organic matters influence its antimicrobial activity. Further investigation by Hachicho et al. (2014) revealed that $P$. aeruginosa exposed to nanoparticles altered its membrane unsaturated fatty acid composition. This alteration causes a change in membrane fluidity making it difficult for the nanoparticles to enter the cell. Graves et al. (2015) also reported that the exposure of microbes to non-lethal concentration of nanoparticles can facilitate the increase in resistance due to the development of mutations that lead to the upregulation and downregulation of many genes.

The upregulation of RND and CDF transporters, P-type ATpase efflux complexes, czcABC and RND family efflux system was also reported as the resistant mechanism of $P$. aeruginosa exposed to different concentrations of $\mathrm{CuONps}$ (Yang et al. 2012; Guo et al. 2017). Other reported mechanisms of bacterial resistance to nanoparticles include, enzymatic transformation of nanoparticles (Palomo-Siguero et al. 2016), biofilm formation/adaptation (Wang et al. 2016), electrostatic repulsion (Abbaszadegan et al. 2015;
Nabavizadeh et al. 2017), pigment production (Ellis et al. 2018), and formation of biomolecule corona around the nanoparticles (Siemer et al. 2019). Panacek et al. (2018) showed that the production of flagellin (adhesive flagellum protein) by $E$. coli and $P$. aeruginosa provoked aggregation of nanoparticles leading to resistance. Faghihzadeh et al. (2018) reported that the production of extracellular substances by E. coli altered the size and zeta potential of AgNps leading to agglomeration and subsequent resistant to AgNps. Furthermore, E. coli exposed to sublethal concentration of $\mathrm{ZnONps}$ was reported to facilitate conjugative transfer of plasmids housing resistant genes (Wang et al. 2018). Qiu et al. (2015) in a similar investigation that exposed $E$. coli to $\mathrm{TiO}_{2} \mathrm{Nps}$, decrease in growth rate of bacteria with subsequent increase in conjugative transfer of genes coding for antibiotic resistance was also noted.

The alteration in the dissolution and release rate of nanomaterials in the biological system in addition to their interaction with the biological fluid can allow the microbes to modify and enhance their adaptation and fitness strategies. It is important to know that prolonged/widespread use of nanoparticles induces the expression of antibiotic resistant genes. Already the production of ROS is one of the key mechanisms of action of nanoparticles. The presence of ROS can lead to a decrease in porins proteins and upregulation of oxidative stress resistant genes. However, the ability of microbes to generate ROS when exposed to nanoparticles can be influenced by interaction with the host environment. The availability of oxygen and light can greatly influence ROS production (Yu et al. 2018). Under aerobic conditions ions can be released while anaerobic conditions can reduce 
the chance of ions release. It was also reported by Chen et al. (2017) that exposure of microbes to AgNps under anaerobic condition decreases the antimicrobial activity of nanoparticles (Chen et al. 2017). Moreover, the alteration in environmental conditions can cause a spontaneous rise in mutation and also trigger genome plasticity which can greatly facilitate resistance to antimicrobial agents and evolutions of strains with increased fitness. Figure 3 summarizes the reported resistant mechanisms of bacteria to nanoparticles. Table 4 shows nanomaterials with photothermal activity as antibacterial agents.

In summary, nanoparticles have long been seen as potential solutions to the increasing resistance to conventional antibiotics and the evolution of multi-drug resistant bacteria. However, reports on the issue of microbial resistance to nanoparticles are gradually emerging. Its frequent clinical application raises the issue of resistance to these potential biomolecules (Barros et al. 2018; Finley et al. 2015). Future studies should explore the possible resistance mechanisms of bacteria to nanoparticles. The major challenges in using nanoparticles as antimicrobial agents are summarized in Table 5.

\section{Discussion}

A large portion of the interest in nanomaterials in clinical practice stems from their drug delivery potential. Interestingly, the use of nanoparticles as a drug delivery system dated back to the early 1990s. Several new generation nanoparticles with new therapeutic modalities have been developed since then. Therapeutic and diagnostic nanoparticles fall under two categories: inorganic (AgNps, AuNps, CuONps, ZnONps, $\mathrm{TiO}_{2} \mathrm{Nps}$, MgONps, CaONps, $\mathrm{Fe}_{2} \mathrm{O}_{3} \mathrm{Nps}, \mathrm{MnO}_{2} \mathrm{Nps}$, etc.) and organic (liposomes, polymeric NPs, micelles, solid lipid Nps (SLNs), nanostructured

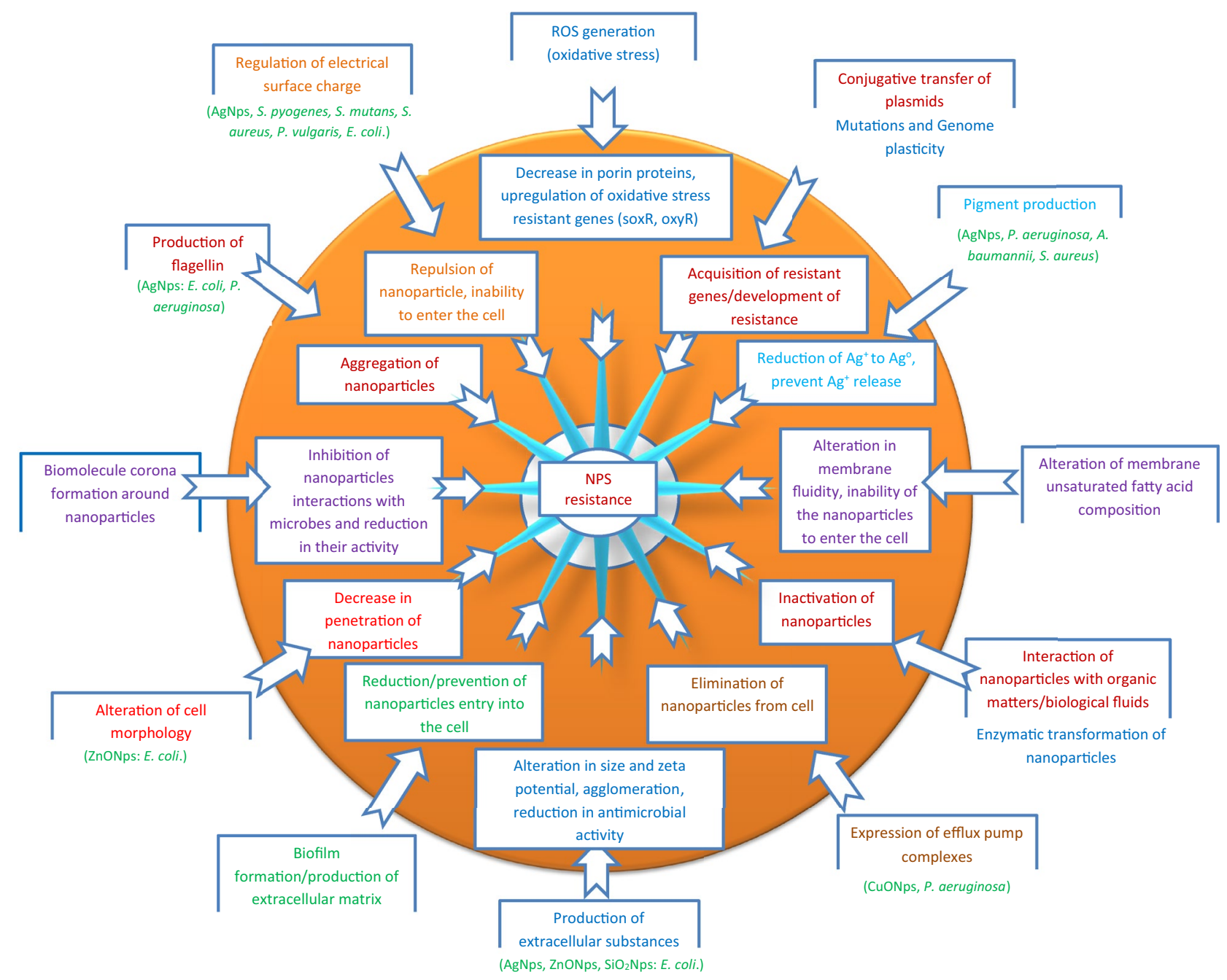

Fig. 3 Resistant mechanisms of bacteria to nanoparticles 


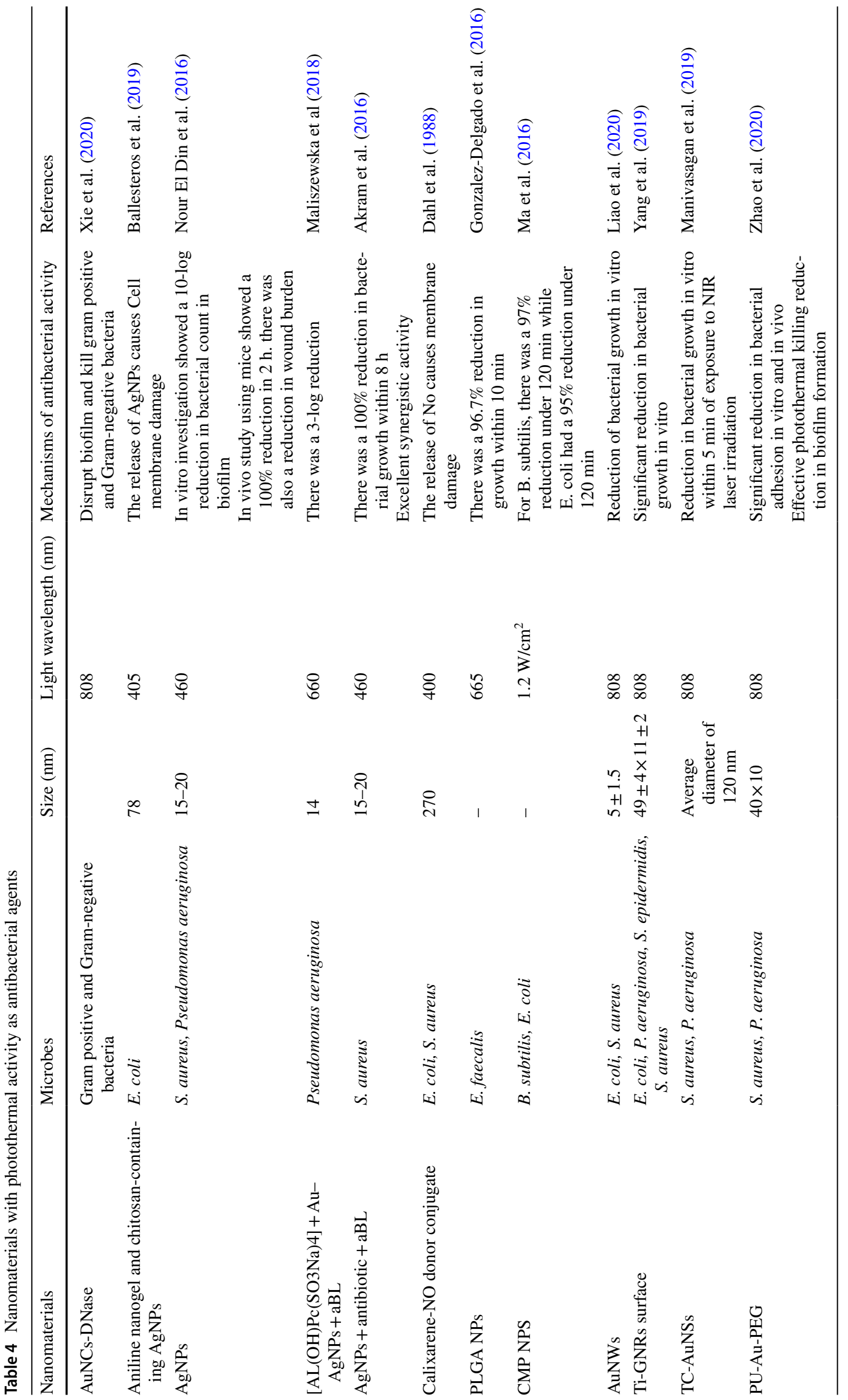


Table 5 Challenges in using nanoparticles as antimicrobial agents

\section{S. No Challenges}

$1 \quad$ Size

2 Shape

$3 \quad$ Aggregate

$4 \quad$ Biodistribution

5 Bioavailability

6 Cytotoxicity

$7 \quad$ Clearance

$8 \quad$ Interactions

$9 \quad$ Dosage

10 Instrumentation

11 Scale-up/optimization

12 Prediction

13 Quality

14 Variation in microbes and human diseases
The size greatly influences antimicrobial potential of nanoparticles. Small size particle has a larger surface areato-volume ratio. Parameters like synthesis method and reducing/stabilizing agents also affect the morphology, size and stability of the synthesized nanoparticles. Thus, controlling these parameters is a major challenge for efficient and highly effective nanoparticles synthesis. Nanoparticles often used as antimicrobial agents usually ranges from 1 to $100 \mathrm{~nm}$. However, particle size range from $10 \mu \mathrm{m}$ to $10 \mathrm{~nm}$ are often more effective because they can easily penetrate and interact with cells. However, synthesizing nanoparticle with such size is often an issue

Nanoparticles are often synthesized in different shapes. AgNps for example have different shapes such as spherical, triangular or pyramid, nanorods, nanowires, flower shaped, octahedral, tetrahedral, nano-prism and nanobars. These shapes can influence the antimicrobial activity of nanoparticles

Nanoparticles can often form aggregates. The formation of these aggregates cause increase in size, thus reducing penetration into the cell and also increases toxicity

Loss of function due to poor bioavailability is a major challenge in developing effective nanoparticle. Low retention rates of nanoparticle also reduce efficiency. Even the accumulation of nanoparticles may be detrimental to the host

Poor dispersion affects nanoparticles activity

Toxicity is a crucial issue in the use of nanomaterials. Local and systemic toxic issues in addition to being detrimental to useful bacteria in human is a major concern (Khan et al. 2016). Both nanoparticle and its degradation products can disrupt pathways involved in blood circulation due to its ability to cause hemolysis. Nanoparticle can also lead to organ dysfunction and damage. Large size nanoparticles are more toxic to the biological system than small size particles (Santos et al. 2014). The use of CuONps, $\mathrm{ZnONps}$ and $\mathrm{TiO}_{2} \mathrm{Nps}$ is mostly limited due to their oxidative and DNA damage (Hemeg 2017). CuONps can specifically trigger hepatoxicity and nephrotoxicity via interaction with components of the cell (Baptista et al. 2018). Although some studies have reported no significant in vivo life-threatening toxicity of nanoparticles, there accumulation could be detrimental to body cells (Zazo et al. 2016; Sengupta et al. 2014; Wei et al. 2015; Zaidi et al. 2017). Nanomaterials administered intravenously can accumulate in different organs in the body. Toxicity evaluation at the cellular and systemic levels is very crucial as it carries great clinical relevance

Nanoparticles elimination from the biological system is generally low. This can lead to their prolonged accumulation in the system. The charge and size of nanoparticle greatly affect their elimination from the biological system. The kidney can eliminate some nanoparticles while those that were not degraded will be retained in the body for a prolong period of time (Lin et al. 2015)

The rapid agglomeration in the use of nanoparticles is a disadvantage in their utilization as an antimicrobial agent. For example, naked $\mathrm{ZnONps}$ can strongly interact with organic acids in biological system which can lead to bioconjugates formation. In addition, the antimicrobial effect of nanoparticles is greatly affected by the presence of amino acids as previously stated. This protein are highly abundant in biological system and are often an issue in getting a safer product design in addition to improved product performance

Dosage is major issue in nanoparticle application. Currently the dose of nanoparticles leading to disruption of cells in vitro are very high and almost not possible to use in humans. As of date, only few clinical studies are available on nanoparticles dosing. For vital therapeutic targets and reduction in toxicity, dosage optimization and evaluation is very crucial (Grumezescu 2018; Hua et al. 2018)

High-throughput technology and equipment are also needed to manufacture nanoparticle. This often make continuous/consistent production of highly quality nanoparticle difficult

Proper guideline formulation for the production, scale-up, physiochemical property characterization, biocompatibility, standardization and protocols to draw a comparison on data origination from in vivo and in vitro experiments are lacking. Inconsistency in size, shape, morphology and other properties may also be evident during large scale production

The efficiency or potency of nanomaterials is mostly very difficult to predict

Producing nanoparticles with uniform size and desired quality and without aggregates is also a major challenge

Diversities in strains and infections caused by different microbes may influence nanoparticles activity and also complicates treatment lipid carriers (NLCs), nanocapsules, nanotubes, quantum dots, dendrimers, emulsions, nanogels, and vesicles). Several inorganic nanoparticles have been successful in clinical studies and have been developed in the clinic for several applications (Anselmo and Mitragotri 2015). Organic nanoparticles have frequently been used in vaccine production and as drug delivery agents. Organic nanoparticles delivered intravenously as treatments for several diseases are also available (Petros and DeSimone 2010). Organic and inorganic nanoparticles have some distinct advantages over 
several intravenously administered pharmaceutical products. Compared to free drug counterparts, many organic nanoparticles can be fabricated to provide enhanced drug protection, controlled release, prolonged circulation and enhanced target to specific tissues (Wang et al. 2012). Moreover, the stimuliresponsive functions emanating from the surface plasmon resonance of inorganic nanoparticles give them an advantage over individual drugs or molecules (Torchilin 2014).

Nanomaterials have been effective against several microbes. A study by Sarwar et al. (2017) showed that ZnONps form a complex with cholera toxin, compromises its structure, and stops its interaction with receptors present in the erythrocytes. Also, M. tuberculosis showed in vitro susceptibility to AgNps (Tabaran et al. 2020), $\mathrm{TiO}_{2}$ (Ramalingam et al. 2019), and SeNps (Estevez et al. 2020), although their mechanism of action remains unclear. AgNps loaded into Ti nanotubes showed promise against biofilm cells formed by MRSA. Its mechanism of action was via the release of $\mathrm{Ag}^{+}$(Cheng et al. 2014b). Also, lipid-coated MSNps loaded with colistin and conjugated with LL-37 showed activity against $P$. aeruginosa-associated pulmonar infections through isoniazid bactericidal effect (Rathnayake et al. 2020).

Moreover, it was reported that Thymus daenensis oil nanoemulsions were effective against bacteria causing pneumococcal infections, and its action mechanism was via oil-bacterial effect (Ghaderi et al. 2017). FA-CP-FA-coated MSNps loaded with ampicillin were shown to be effective against $S$. aureus and $E$. coli and could be utilized in treating S. aureus and E. coli-related infections (Chen et al. 2018). Thus, nanoparticles could become an indispensable tool in the treatment of various infections. The use of nanoparticles in the treatment of both chronic and acute respiratory disease was extensively summarized in a recent article by de Menezes et al. (2021).

Also, the ability of nanoparticles to interact with different components of bacteria and exert their antimicrobial mechanisms increases with an increase in the surface/ volume ratio of the nanoparticles (Azam et al. 2012). The smaller the size of the nanoparticles, the greater the surface area/volume ratio. Agnihotri et al. (2014) synthesized different AgNps with different sizes and observed that their antibacterial effect depends on their dose and size. Studies have shown that the size of nanoparticles is one of the main factors responsible for their antibacterial activity. However, this depends on the type of synthesis, precursors, and parameters used. Size remains one of the vital factors responsible for the bactericidal effects of nanoparticles (Helmlinger et al. 2016). Nanoparticles with size $<10 \mathrm{~nm}$ can penetrate to the interior of the bacterial cell and exert their antibacterial effect (Khalandi et al. 2017), while that $>10 \mathrm{~nm}$ cannot penetrate the interior of the bacterial cell (Butler et al. 2015; Wang et al. 2011). A recent investigation by Osonga et al.
(2020) reported that the antimicrobial activities of AgNps and AuNps were dependent on size, with no associated toxicity. Furthermore, the surface charge of nanoparticles is also a crucial factor affecting their antimicrobial activity (Abbaszadegan et al. 2015). Moreover, the shape of nanoparticles also determines their antibacterial activity (Raza et al. 2016).

AgNps are highly effective against bacteria. At lower doses, AgNps show low toxicity towards humans (Shahverdi et al. 2007). Chen et al. showed that AuNps with sizes of 8-37 nm were more toxic while AuNps with sizes between 3 and $100 \mathrm{~nm}$ were less toxic (Chen et al. 2009). The toxicity was attributed to the synthesis methods and organic reducing and capping agents during the synthesis. Often, there are conflicts in findings regarding the toxic effects of nanoparticles. These differences are broadly due to a lack of standardized experimental procedures (Tao 2018). Sometimes, similar experiments lead to different conclusions. Differences in experimental techniques, doses, and administration routes have not helped the matter. This issue needs proper attention and may require a regional or international regulatory body.

Studies have shown that nanoparticles conjugated with small molecules (e.g., drugs, antibodies, antibiotics, vaccines) are usually more effective than the individual nanoparticles. The combination of nanoparticles with antibiotics greatly reduces the dosage of antibiotics to be administered. This helps to reduce toxicity associated with several antibiotics and helps to reduce resistance acquisition. Combination therapy will pave the way for nanoparticles to be used as adjuncts to existing antimicrobials; thus, helping to reduce resistance associated with most microbes. Impregnation of already available antibiotics with nanoparticles can help improve antimicrobial activity against resistant microbes. More attention should be given to synergistic interactions of nanoparticles with already available antimicrobial agents. However, it should be emphasized that the antimicrobial effect of antibiotic conjugated (impregnated) with nanoparticles depends on the antibiotics used.

Importantly, before nanoparticles can be efficiently incorporated into biological systems, clear insights regarding their stability and interaction with biological fluids (e.g., plasma, serum, proteins, lipids, electrolytes, and metabolites) are needed. The activity of nanoparticles may be influenced by their interactions with protein molecules present in biological systems. The proteins (ligands) can attach to the surface of nanomaterials and influence their dissolution, as well as their antimicrobial and cytotoxic effects. Although it has been reported that surface coating of nanoparticles could prevent their interactions with biological fluids, recent studies have proven that coating the surface of nanoparticles doesn't prevent their interaction with biological fluid nor improve their antimicrobial potential. Therefore, the interaction of nanoparticles with biological fluids is a crucial 
area that needs to be exploited. Future studies should look at undesirable off-target interactions of combined nanoparticles and nanoparticles combined with antibiotics.

It is imperative to also look at the dosage of nanoparticles. Drugs that are useful at low doses may exhibit high toxicity at high doses. The doses reported in most studies vary, and the number of cells exposed is not usually reported. Future studies should look at the toxicity. Due to the promising potentials of nanoparticles, one important goal of the nanomaterials research community is to synthesize nanoparticles or nanoparticles that can conjugate very effectively at low doses (concentration). Studies should focus on non-toxic biological materials that can accelerate the potency of nanoparticles without increasing the concentration that might be toxic to biological systems. The combination of different nanoparticles can also help to reduce the dosage. Nanocomposites are also more effective than individual nanoparticles. Thus, more attention should be given to their formulation. Moreover, synthesizing nanoparticles that can bind to proteins, polysaccharides, or small bioactive compounds may be crucial in enhancing their antimicrobial potentials.

The underlying mechanism behind the activity of nanoparticles is yet to be adequately understood. The non-availability of a precise approach for in vitro analysis, in addition to the complexity of the bacterial membrane, makes it difficult to gain proper insight into the exact mechanism for antimicrobial activity of nanoparticles. To efficiently evaluate the accurate therapeutic potentials of nanoparticles and unmask the microbial response to these agents, in vivo studies are indispensable. In vivo studies are essential to elucidate their utility in biological systems fully. Therefore, further studies on the nanomaterial activity at structural, genetic, and proteomic levels are needed.

Furthermore, the frequent clinical application of nanoparticles raises the issue of resistance to these potential agents. Already, microbial resistance to nanoparticles has been summarized above. However, mutation has been one of the reported bacterial mechanisms of resistance to nanoparticles (Graves et al. 2015). Both metal and metal oxide nanoparticles seem to stimulate the co-selection and co-expression of antibiotic resistance genes. In an investigation by Wang et al. (2018), E. coli cultures and aquatic microbiota were exposed to sublethal concentrations of $\mathrm{ZnONps}$. The exposure triggered the conjugative transfer of drug-resistance plasmids. The exposure causes an increase in the cell membrane permeability, increasing horizontal gene transfer (HGT) frequency. A similar finding was previously reported by Qiu et al. (2015), who exposed E. coli to a high concentration of $\mathrm{TiO}_{2} \mathrm{Nps}$.

It has also been reported that bacteria exposed to $\mathrm{AgNps}$ upregulate genes responsible for protecting against oxidative stress (soxR, oxyR, sodB, sodA) and genes responsible for converting hydrogen peroxide to oxygen (katE and katG)
(Gou et al. 2010). In their investigation, Zhang et al. (2018) showed that $\mathrm{Al}_{2} \mathrm{O}_{3} \mathrm{Nps}$ and $\mathrm{ZnONps}$ accelerate mutagenesis and the emergence of multiple resistance. According to the investigation, two nanoparticles increased mutation frequency and an increase in multi-antibiotic resistance in the mutation compared to the controls. The nanoparticles also enhanced intracellular ROS, leading to a rise in the frequency of antibiotic resistance mutagenesis.

Finally, photodynamic light therapy is a promising approach for treating infections, especially those due to ESKAPE pathogens. It is a minimally invasive and inexpensive approach to combat antimicrobial resistance. It is highly effective, especially in topical applications. PDT coadministered or conjugated with antibiotics, nanoparticles, antimicrobial peptides, or efflux pump inhibitors show an excellent effect. However, comparison of the efficacy of the different combinations is always difficult due to lack of standardization.

\section{Conclusion}

It is becoming obvious that nanoparticles have the potential to change clinical care by improving current therapies or introducing new therapeutic agents. For translation into clinical practice, studies on the toxicity and biocompatibility of the different combinations are needed. To date, the resistance mechanisms of microbes to nanoparticles have not been properly explored and demands adequate attention. To avoid the issue of resistance associated with conventional antibiotics, an understanding of the adaptive mechanisms of microbial resistance to nanoparticles is warranted and should be exploited in future studies. In the years to come, nanomaterials will innovate the world of technology due to their unique properties. However, one important target area of nanoparticle research should be to reduce their toxic effect on humans and enhance their bioavailability and stability.

\section{References}

Abbaszadegan A, Ghabramani Y, Gholami A, Hemmateenejad B, Dorostkar S, Nabavizadeh M, Sharghi H (2015) The effect of change at the surface of silver nanoparticles on antimicrobial activity against gram-positive and gram-negative bacteria: a preliminary study. J Nanomater 720654:8

Abdel-Raouf N, Al-Enazi NM, Ibraheem IBM (2017) Green biosynthesis of gold nanoparticles using Galaxaura elongata and characterization of their antibacterial activity. Arabian J Chem 10:S3029-S3039

Abdul-Hussan I, Abbas AK, Ibrahim IM, Shallal ZS (2018) Characterization and antimicrobial effects of titanium dioxide nanoparticles produced by laser ablation. Indian J Nat Sci 8(49):14286-14292 
Abo-Shama UH, El-Gendy H, Mousa WS, Hamouda RA, Yousuf WE, Hetta HF, Abdeen EE (2020) Synergistic and antagonistic effects of metal nanoparticles in combination with antibiotics against some reference strains of pathogenic microorganisms. Infect Drug Resist 13:351-362

Abuayyash A, Ziegler N, Gessmann J, Sengstock C, Schildhauer TA, Ludwig A, Köller M (2018) Antibacterial efficacy of sacrifical anode thin films combining silver with platinum group elements within a bacteria-containing human plasma clot. Adv Eng Mater 20:1700493

Adebayo-Tayo B, Salaam A, Ajubade A (2019) Green synthesis of silver nanoparticles using Oscillatoria sp. extract, its antibacterial, antibiofilm potential and cytotoxicity activity. Heliyon 5:e02502

Agnihotri S, Mukherji S, Mukherji S (2014) Size-controlled silver nanoparticles synthesized over the range 5-100 $\mathrm{nm}$ using the same protocol and their antibacterial efficacy. Rsc Adv 4:3974-3983

Akram FE, El-Tayeb T, Abou-Aisha K, El-Azizi M (2016) A combination of silver nanoparticles and visible blue light enhances the antibacterial efficacy of ineffective antibiotics against methicillin-resistant Staphylococcus aureus (MRSA). Ann Clin Microbiol Antimicrob 15:48

Akter S, Huq MdA (2020) Biologically rapid synthesis of silver nanoparticles by Sphinogobium spp. MAH-11T and their antibacterial activity and mechanisms investigation against drug-resistant pathogenic microbes. Artif Cells Nanomed Biotechnol 48:1

Al-Sharqi A, Apun K, Vincent M, Kanakaraju D, Bilung LM, Sam MSH (2019) Investigation of the antibacterial activity of AgNps conjugated with a specific antibody against Staphylococcus aureus after photoactivation. J Appl Microbiol 128:102-115

Ansari MA, Murali M, Prasad D, Alzohairy MA, Almatroudi A, Almomary MN, Udayashankar AC, Singh SB, Asiri SMM, Ashwini BS, Gowtham HG, Kalegowda N, Amruthesh KN, Lakshmeesha TR, Niranjana SR (2020) Cinnamomum verum bark extract mediated green synthesis of $\mathrm{ZnO}$ nanoparticles and their antibacterial potentiality. Biomolecules 10:336

Anselmo AC, Mitragotri S (2015) A review of clinical translation of inorganic nanoparticles. AAPS J 17(5):1041-1054

Anselmo AC, Mitragotri S (2016) Nanoparticles in the clinic. Bioeng Transl Med 1(1):10-29

Arya G, Sharma N, Mankamna R, Nimesh S (2019) Antimicrobial silver nanoparticles: future of nanomaterials. In: Prasad R (ed) Microbial nanobionics. Nanotechnology in the life sciences. Springer, Cham

Asemani M, Anarjan N (2019) Green synthesis of copper oxide nanoparticles using Juglans regia leaf extract and assessment of their physic-chemical and biological properties. Green Process Synth 8(1):557-567

Azam A, Ahmed AS, Oves M, Khan M, Memic A (2012) Size-dependent antimicrobial properties of $\mathrm{CuO}$ nanoparticles against grampositive and-negative bacterial strains. Int J Nanomed 7:3527

Badetti E, Calgaro L, Falchi L, Bonetto A, Bettiol C, Leonetti B, Ambrosi E, Zendri E, Marcomini A (2019) Interaction between copper oxide nanoparticles and amino acids: influence on the bacterial activity. Nanomaterials 9:792

Balaganesh AS, Sengidaan R, Ranjithkumar R, Chandarshekar B (2018) Synthesis and characterization of porous calcium oxide nanoparticles (CaoNps). Int J Innov Technol Exploring Eng 8(2S):2278-2757

Ballesteros CAS, Bernardi JC, Correa DS, Zucolotto V (2019) Controlled release of silver nanoparticles contained in photoresponsive nanogels. ACS Appl Bio Mater 2(2):644-653

Bankier C, Matharu RK, Cheong YK, Ren GG, Cloutman-Green E, Ciric L (2019) Synergistic antibacterial effects of metallic nanoparticle combinations. Sci Rep 9:16074

Banoee M, Seif S, Nazari ZE, Jafari-Fesharaki P, Shahverdi HR, Moballegh A, Moghaddam KM, Shahverdi AR (2010) ZnO nanoparticles enhanced antibacterial activity of ciprofloxacin against Staphylococcus aureus and Escherichia coli. J Biomed Mater Res B 93:557-561

Bao Z, Liu X, Liu Y, Liu H, Zhao K (2016) Near-infrared light-responsive inorganic nanomaterials for photothermal therapy. Asian $\mathrm{J}$ Pharm Sci 11(3):349-364

Baptista PV, Mccusker MP, Carvalho A, Ferreira DA, Mohan NM, Martins M, Fernandes AR (2018) Nano-strategies to fight multidrug resistant bacteria - "a battle of the titans." Front Microbiol 9:1441

Barros CHN, Fulaz S, Stanisic D, Tasic L (2018) Biogenic nanosilver against multidrug-resistant bacteria (MDRB). Antibiotics (basel). https://doi.org/10.3390/antibiotics7030069

Bhuyan T, Mishra K, Khanuja M, Prasad R, Varma A (2015) Biosynthesis of zinc oxide nanoparticles from Azadirachta indica for antibacterial and photocatalytic applications. Mater Sci Semicond Process 32:55-61

Bilal M, Rasheed T, Iqbal HMN, Hu H, Zhang X (2017) Silver nanoparticles: biosynthesis and antimicrobial potentialities. Int $\mathbf{J}$ Pharmacol 13(7):832-845

Bogdanović U, Lazić V, Vodnik V, Budimir M, Marković Z, Dimitrijević S (2014) Copper nanoparticles with high antimicrobial activity. Mater Lett 128:75-78

Brown AN, Smith K, Samuels TA, Lu J, Obare SO, Scott ME (2012) Nanoparticles functionalized with ampicillin destroy multiple antibiotic-resistant isolates of Pseudomonas aeruginosa and Enterobacter aerogenes and methicillin-resistant Staphylococcus aureus. Appl Environ Microbiol 78(8):2768-2774

Butt AR, Ejaz S, Baron JC, Ikram M, Ah S (2015) Cao nanoparticles as a potential drug delivery agent for biomedical applications. Dig J Nanomater Biostruct 10:799-809

Butler KS, Peeler DJ, Casey BJ, Dair BJ, Elespuru RK (2015) Silver nanoparticles: correlating nanoparticle size and cellular uptake with genotoxicity. Mutagenesis 30:577-591

Canaparo R, Foglietta F, Giuntini F, Pepa CD, Dosio F, Serpe L (2019) Recent development in antibacterial therapy: focus on stimuliresponsive drug-delivery systems and therapeutic nanoparitcles. Molecules 24:1991

Chamundeeswari M, Sobhana SS, Jacob JP, Kumar MG, Devi MP, Sastry TP, Mandal AB (2010) Preparation, characterization and evaluation of a biopolymeric gold nanocomposite with antimicrobial activity. Biotechnol Appl Biochem 55:29-35

Chauhan M, Jasrotia T, Kaur G, Prakash C, Kumar R, Dilbaghi N, Chaudhary GR, Kumar S (2019) Investigating the efficiency of $\alpha$-Bismuth zinc oxide heterostructure composite/UV-LED in methylene blue dye removal and evaluation of its antimicrobial activity. Environ Res 180:108857

Chen H, Zhao Y (2018) Applications of light-responsive systems for cancer theraostics. ACS Appl Mater Interfaces 10:21021-21034

Chen Y-S, Hung Y-C, Liau I, Huang GS (2009) Assessment of the in vivo toxicity of gold nanoparticles. Nanoscale Res Lett 4:858

Chen Z, Yang P, Yuan Z, Guo J (2017) Aerobic condition enhances bacteriostatic effects of silver nanoparticles in aquatic environment: an antimicrobial study on Pseudomonas aeruginosa. Sci Rep 7:7398

Chen X, Liu Y, Lin A, Huang N, Long L, Gang Y, Liu J (2018) Folic acid-modified mesoporous silica nanoparticles with ph-responsiveness loaded with amp for an enhanced effect against antidrug-resistant bacteria by overcoming efflux pump systems. Biomater Sci 6:1923-1935

Cheng L, Wang C, Feng L, Yang K, Liu Z (2014a) Functional nanomaterials for phototherapies of cancer. Chem Rev 114:10869-10939

Cheng H, Li Y, Huo K, Gao B, Xiong W (2014b) Long-lasting in vivo and in vitro antibacterial ability of nanostructured titania coating incorporated with silver nanoparticles: antibacterial ability of silver nanoparticles. J Biomed Mater Res 102:3488-3499 
Chiang W-L, Lin T-T, Sureshbabu R, Chia W-T, Hsiao H-C, Liu H-Y, Yang C-M, Sung H-W (2015) A rapid drug release system with a NIR light-activated molecular switch for dual-modality photothermal/antibiotic treatments of subcutaneous abscesses. J Controlled Release 199:53-62

Cobos M, De-La-Pinta I, Quindos G, Fernandez MJ, Fernendez MD (2020) Graphene oxide-silver nanoparticle nanohybrids: synthesis, characterization and antimicrobial properties. Nanomaterial 10:376

Cui Y, Zhao Y, Tian Y, Zhang W, Lü X, Jiang X (2012) The molecular mechanism of action of bactericidal gold nanoparticles on Escherichia coli. Biomaterials 33(7):2327-2333

Dahl TA, Midden WR, Neckers DC (1988) Comparison of photodynamic action by rose Bengal in gram-positive and gram-negative bacteria. Photochem Photobiol 48:607-612

De Menezes BRC, Rodrigues KF, Schatkosi VM, Pereira RM, Ribas RG, Montanheiro TLA, Thim GP (2021) Current advances in drug delivery of nanoparticles for respiratory disease treatment. J Mater Chem B 9:1745-1761

DeAlba-Montero I, Guajardo-Pacheco J, Morales-Sanchez E, AraujoMartinez R, Loredo-Becerra GM, Martinez-Castanon GA, Ruiz F, Compean Jasso ME (2017) Antimicrobial properties of copper nanoparticles and amino acid chelated copper nanoparticles produced by using a soya extract. Bioinorg Chem Appl 2017:1064918

Deng H, McShan D, Zhang Y, Sinha SS, Arslan Z, Ray PC, You H (2016) Mechanistic study of the synergistic antibacterial activity of combined silver nanoparticles and common antibiotics. Environ Sci Technol 50(16):8840-8848

Dong Y, Zhu H, Shen Y, Zhang W, Zhang L (2019) Antibacterial activity of silver Nanoparticles of different particles against Vibrio natriegens. PLoS ONE 14(9):e0222322

Dos Santos CA, Seckler MM, Ingle AP, Gupta I, Galdiero S, Galdiero M, Gade A, Rai M (2014) Silver nanoparticles: therapeutical uses, toxicity, and safety issues. J Pharm Sci 103:1931-1944

Durán N, Marcato PD, Conti RD, Alves OL, Costa FTM, Brocchi M (2010) Potential use of silver nanoparticles on pathogenic bacteria, their toxicity and possible mechanisms of action. J Braz Chem Soc 21:949-959

Dye C (2014) After 2015: infectious diseases in a new era of health and development. Philos Trans R Soc Lond B 369:20130426

El-Batal AI, El-Sayyad GS, El-Ghamery A, Gobara M (2017) Response surface methodology optimization of melanin production by Streptomyces cyaneus and synthesis of copper oxide nanoparticles using gamma radiation. J Clust Sci 28:1083-1112

Ellis DH, Maurer-Gardner EI, Sulentic CE, Hussain SM (2018) Silver nanoparticle antibacterial efficacy and resistance development in key bacterial species. Biomed Phys Eng Express 5:015013

El-Sayed MT, El-Sayed AS (2020) Biocidal activity of metal nanoparticles synthesized by Fusarium against multidrug-resistant bacteria and mycotoxigenic fungi. J Microbiol Biotechnol 30(2):226-236

Escarcega-Gonzalez CE, Garza-Cervantes JA, Vazquez-Rodriguez A, Montelongo-peralta LZ, Trerino-Gonzalez MT, Barriga-Castro DE, Saucedo-Salazar EM, Chavez-Morales RM, Regalado-Soto DI, Trevino-Gonzalez FM, Carvazco-Rosales JL, VillalobosCruz R (2018) In vitro antimicrobial activity of silver nanoparticles produced via a green chemistry synthesis using Acacia rigidula as a reducing and capping agent. Int $\mathbf{J}$ Nanomed 13:2349-2363

Estevez H, Palacios A, Gil D, Anguita J, Vallet-Regi M, González B, Prados-Rosales R, Luque-Garcia JL (2020) Antimycobacterial effect of selenium nanoparticles on mycobacterium tuberculosis. Front Microbiol 11:800

Faghihzadeh F, Anaya N, Astudillo-Castro C, Oyanedel-Craver V (2018) Kinetic, metabolic and macromolecular response of bacteria to chronic nanoparticle exposure in continuous culture. Environ Sci Nano 5:1386-1396

Fan Y, Pauer AC, Gonzales AA, Fenniri H (2019) Enhanced antibacterial activity of ampicillin conjugated to gold nanoparticles on PEGylated rosette nanotubes. Int J Nanomed 14:7281-7289

Farooq U, Ahmad T, Khan A, Sarwar R, Shafiq J, Raza Y, Ahmed A, Ullah S, Ur Rehman N, Al-Harrasi A (2019) Rifampicin conjugated silver nanoparticles: a new arena for development of antibiofilm potential against methicillin resistant Staphylococcus aureus and Klebsiella pneumonia. Int J Nanomed 14:3983-3993

Farzana R, Iqra P, Shafaq F, Sumaira S, Zakia K, Hunaiza T, Husna M (2017) Antimicrobial behavior of zinc oxide nanoparticles and $\beta$-lactam antibiotics against pathogenic bacteria. Arch Clin Microbiol 8(4):57

Fayaz AM, Balaji K, Girilal M, Yadav R, Kalaichelvan PT, Venketesan $R$ (2010) Biogenic synthesis of silver nanoparticles and their synergistic effect with antibiotics: a study against gram-positive and gram-negative bacteria. Nanomedicine 6:103-109

Fenollar F, Mediannikov O (2018) Emerging infectious diseases in Africa in the 21st century. N Microbe N Infect 26:S10-S18

Finley PJ, Norton R, Austin C, Mitchell A, Zank S, Durham P (2015) Unprecedented silver resistance in clinically isolated Enterobacteriaceae: major implications for burn and wound management. Antimicrob Agents Chemother 59:4734-4741

Flores-Lopez L, Espinoza-Gomez H, Somanathan R (2019) Silver nanoparticles: electron transfer, reactive oxygen species, oxidative stress, beneficial and toxicological effects. Mini Review J Appl Toxicol 39(1):16-26

Folorunso A, Akintelu S, Oyebamiji AK, Ajaji S, Abiola B, Abdusalam I, Morakinyo A (2019) Biosynthesis, characterization and antimicrobial activity of gold nanoparticles from leaf extracts of Annona muricata. J Nanostructure Chem 9:111-117

Foster HA, Ditta IB, Varghese S, Steele A (2011) Photocatalytic disinfection using titanium dioxide: spectrum and mechanism of antimicrobial activity. Appl Microbiol Biotechnol 90(1):1847-1868

Gabrielyan L, Hakobyan L, Horhannisyan A, Trchounian A (2019) Effects of iron oxide (Fe3O4) nanoparticles on E. coli antibiotic resistant strains. J Appl Microbiol 26:4

Galanzha EI, Shashkov E, Sarimollaoglu M, Beenken KE, Basnakian AG, Shirtliff ME, Kim J-W, Smeltzer MS, Zharov VP (2012) In vivo magnetic enrichment, photoacoustic diagnosis, and photothermal purging of infected blood using multifunctional gold and magnetic nanoparticles. PLoS ONE 7(9):e45557

Garza-Cervantees JA, Escarcega G, Marichal-Cancino BA, Lopez EDB, Mendiola-Garza G, Marichal-Cancino BA, Lopez-Vazquez MA, Morones-Ramirez JR (2019) Antimicrobial and antibiofilm activity of biopolymer-Ni, Zn nanoparticles biocomposites sythesized using $R$. mucilaginosa UANL-00IL exopolysaccharide as a capping agent. Int J Nanomed 14:2557-2571

Ghaderi L, Moghimi R, Aliahmadi A, McClements DJ, Rafati H (2017) Development of antimicrobial nanoemulsion-based delivery systems against selected pathogenic bacteria using a thymol-rich Thymus daenensis essential oil. J Appl Microbiol 123:832-840

Ghasemi F, Halal R (2016) Antimicrobial action of zinc oxide nanoparticles in combination with ciprofloxacin and ceftazidime against multi drug resistant Acinetobacter baumannii. J Glob Antimicrob Resist 6:118-122

Global Health Estimates (2016) Deaths by cause, age, sex, by country and by region, 2000-2016. World Health Organization, Geneva

González-Delgado JA, Castro PM, Machado A et al (2016) Hydrogels containing porphyrin-loaded nanoparticles for topical photodynamic applications. Int J Pharm 510(1):221-231 
Gou N, Onnis-Hayden A, Gu AZ (2010) Mechanistic toxicity assessment of nanomaterials by whole-cell-array stress genes expression analysis. Environ Sci Technol 44:5964-5970

Gounani Z, Asadollahi MA, Pedersen JN, Lyngso J, Pedersen JS, Arpanaei A, Meyer RL (2018) Mesoporous silver nanoparticles carrying multiple antibiotics provide enhanced synergistic effect and improved biocompatibility. Colloids Surf B 175:498-508

Graves JL Jr, Tajkarimi M, Cunningham Q, Campbell A, Nonga H, Harrison SH, Barrick JE (2015) Rapid evolution of silver nanoparticle resistance in Escherichia coli. Front Genet 6:42

Grumezescu AM (2018) Nanoscale fabrication, optimization, scale-up and biological aspects of pharmaceutical nanotechnology. Elsevier Inc., London

Guo J, Gao SH, Lu J, Bond PL, Verstraete W, Yuan Z (2017) Copper oxide nanoparticles induce lysogenic bacteriophage and metalresistance genes in Pseudomonas aeruginosa PAO1. ACS Appl Mater Interfaces 9:22298-22307

Gurav VL, Samant RA, Manjaer SB, Patil UK, Solkar SR, Moghe SS (2020) Biosynthesis of calcium oxide nanoparticles using Ocimum sanctum (Tulsi) leaf extracts and screening its antimicrobial activity. Asian J Nanosci Mater 3:115-120

Habibipour R, Moradi-Haghgou L, Farmany A (2019) Green synthesis of AgNps@PPE and its Pseudomonas aeruginosa biofilm formation activity compared to pomegranate peel extract. Int $\mathbf{J}$ Nanomed 14:6891-6899

Hachicho N, Hoffmann P, Ahlert K, Heipieper VHJ (2014) Effect of silver nanoparticles and silver ions on growth and adaptive response mechanisms of Pseudomonas putida mt-2. FEMS Microbiol Lett 355:71-77

Hall CW, Mah TF (2017) Molecular mechanisms of biofilm-based antibiotic resistance and tolerance in pathogenic bacteria. FEMS Microbiol Rev 41(3):276-301

Hall-Stoodley L, Costerton JW, Stoodley P (2004) Bacterial biofilms: from the natural environment to infectious diseases. Nat Rev Microbiol 2(2):95-108

Halstead FD, Thwaite JE, Burt R, Laws TR, Raguse M, Moeller R et al (2016) Antibacterial activity of blue light against nosocomial wound pathogens growing planktonically and as mature biofilms. Appl Environ Microbiol 82:4006-4016

Hamouda RA, Hussein MH, Abo-elmagd RA, Bawazir SS (2019) Synthesis and biological characterization of silver nanoparticles derived from the Cyanobacterium oscillatoria limnetica. Sci Rep 9:13071

He Y, Ingudam S, Reed S, Gehring A, Strobaugh TP Jr, Irwin P (2016) Study on the mechanism of antibacterial action of magnesium oxide nanoparticles against foodborne pathogens. J Biotechnol 14:54

Helmlinger J, Sengstock C, Groß-Heitfeld C, Mayer C, Schildhauer T, Köller M, Epple M (2016) Silver nanoparticles with different size and shape: equal cytotoxicity, but different antibacterial effects. RSC Adv 6:18490-18501

Hemeg HA (2017) Nanomaterials for alternative antibacterial therapy. Int J Nanomed 12:8211-8225

Hossain MdM, Polash SA, Takikawa M, Shubhra RD, Saha T, Islam Z, Hossain S, Hasan MdA, Takeoka S, Sarker SR (2019) Investigation of the antibacterial activity and in vivo cytotoxicity of biogenic silver nanoparticles as potent therapeutics. Front Bioeng Biotechnol 9:239

Hsiao C-W, Chen H-L, Liao Z-X, Sureshbabu R, Hsiao H-C, Lin S-J, Chang Y, Sung H-W (2015) Effective photothermal killing of pathogenic bacteria by using spatially tunable colloidal gels with nano-localized heating sources. Adv Funct Mater 25(5):721-728

Hu B, Zhang L-P, Chen X-W, Wang J-H (2013) Gold nanorodcovered kanamycin-loaded hollow SiO2 (HSKAurod) nanocapsules for drug delivery and photothermal therapy on bacteria. Nanoscale 5:246-252

Hu M, Li C, Li X, Zhou M, Sun J, Sheng F, Shi S, Lu L (2017) Zinc oxide/silver bimetallic nanoencapsulated in Prp/PCL nanofibres for improved antibacterial activity. Artif Cells Nanomed Biotecnol 46(6): 1248-1257

Hu X, Saravanakumar K, Jin T, Wang M-H (2019) Mycosynthesis, characterization, anticancer and antibacterial activity of silver nanoparticles from endophytic fungus Talaromyces purpureogenus. Int J Nanomed 14:3427-3438

Hua S, de Matos MBC, Metselaar JM, Storm G (2018) Current trends and challenges in the clinical translation of nanoparticulate nanomedicines: pathways for translational development and commercialization. Front Pharmacol 9:790

Huang F, Gao Y, Zhang Y, Cheng T, Ou H, Yang L-J, Liu J, Shi L, Liu J (2020) Silver-decorated polymeric micelles combined with curcumin for enhanced antibacterial agents. J Nanosci Nanotechnol 15:3574

Huq MdA (2020) Green synthesis of silver nanoparticles using Pseudoduganella eburnean MAHUQ-39 and their antimicrobial mechanisms investigation against drug resistant human pathogens. Int J Mol Sci 21:1510

Hussain S, Joo J, Kang J, Kim B, Braun GB, She Z-G, Kim D et al (2018) Antibiotic-loaded nanoparticles targeted to the site of infection enhance antibacterial efficacy. Nat Biomed Eng 2:95-103

Ijaz F, Shahid S, Khan SA, Ahmad W, Zaman S (2017) Green synthesis of copper oxide nanoparticles using Abutilon indicum leaf extract: antimicrobial antioxidant and photocatalytic dye degradation activities. Trop J Pharm Res 16(4):743-753

Jagathesan GP, Rajiv P (2018) Biosynthesis and characterization of iron oxide nanoparticles using Eichhornia crassipes leaf extract and assessing their antibacterial activity. Biocatal Agric Biotechnol 13:90-94

Jain PK, Huang X, El-Sayed IH, El-Sayed MA (2007) Review of some interesting surface plasmon resonance enhanced properties of noble metal nanoparticles and their applications to biosystems. Plasmonics 2(3):107-118

Jaworski S, Wierzbicki M, Sawosz E, Jung A, Gielerak G, Biernat J, Jaremek H, Lojkowski W et al (2018) Chwalibog graphene oxide-based nanocomposites decorated with silver nanoparticles as an antibacterial agent. Nanoscale Res Lett 13:116

Ji H, Dong K, Yan Z, Ding C, Chen Z, Ren J, Qu X (2016) Bacterial hyaluronidase self-triggered prodrug release for chemophotothermal synergistic treatment of bacterial infection. Small 12:6200-6206

Jordan S, Hutchings MI, Mascher T (2008) Cell envelope stress response in Gram-positive bacteria. FEMS Microbiol Rev 32:107-146

Kalita S, Kandimalla R, Sharma KK, Kataki AC, Deka M, Kotoky J (2016) Amoxicillin functionalized gold nanoparticles reverts MRSA resistance. Mater Sci Eng 61:720-727

Katayama B, Ozawa T, Morimoto K, Awazu K, Ito N, Honda N et al (2018) Enhanced sterilization and healing of cutaneous pseudomonas infection using 5-aminolevulinic acid as a photosensitizer with 410-nm LED light. J Dermatol Sci 90:323-331

Kaur P, Nene AG, Sharma D, Somani PR, Tuli HS (2019) Synergistic effect of copper nanoparticles and antibiotics to enhance antibacterial potential. Bio Mater Technol 1(1):33-47

Kedziora A, Speruda M, Kezyzewska E, Rybka J, Lukowiak A, BuglaPl-ploskoriska G (2018) Similarities and differences between silver ions and silver in nanoforms as antibacterial agents. Int $\mathrm{J}$ Mol Sci 19(2):444

Khalandi B, Asadi N, Milani M, Davaran S, Abadi AJN, Abasi E, Akbarzadeh A (2017) A review on potential role of silver 
nanoparticles and possible mechanisms of their actions on bacteria. Drug Res 11:70-76

Khan ST, Musarrat J, Al-Khedhairy AA (2016) Countering drug resistance, infectious diseases, and sepsis using metal and metal oxides nanoparticles: current status. Colloids Surf B 146:70-83

Kim SH, Kang EB, Jeong CJ, Sharker SMd, Ln I, Park SY (2015) Light controllable surface coating for effective photothermal killing of bacteria. ACS Appl Mater Inter 7(28):15600-15606

Korupalli C, Huang CC, Lin W-C, Pan W-Y, Lin P-Y, Wan W-L, Li M-J, Chang Y, Sung H-W (2017) Acidity-triggered charge-convertible nanoparticles that can cause bacterium-specific aggregation in situ to enhance photothermal ablation of focal infection. Biomaterials 116:1-9

Krishnamoorthy K, Manivannan G, Kim SJ, Jeyasubramanian K, Premanathan M (2012) Antimicrobial activity of MgO nanoparticles based on lipid peroxidation by oxygen vacancy. J Nanoparticles Res 14:1063

Kuang Y, Zhang K, Cao Y, Chen X, Wang K, Liu M, Pei R (2017) Hydrophobic IR-780 dye encapsulated in cRGD-conjugated solid lipid $\mathrm{n}$ for NIR imaging-guided photothermal therapy. ACS Appl Mater Inter 9:12217-12226

Kumar A, Pandey AK, Singh SS, Shanker R, Dhawan A (2011) Engineered $\mathrm{ZnO}$ and $\mathrm{TiO}(2)$ nanoparticles induce oxidative stress and DNA damage leading to reduced viability of Escherichia coli. Free Radic Biol Med 51:1872-1881

Kundu S (2017) Gold nanoparticles: their application as antimicrobial agents and vehicles of gene delivery. Adv Biotechnol Microbiol 4:5

Landage KS, Arabade GK, Khanna P, Bhongale CT (2020) Biological approach to synthesize $\mathrm{TiO}_{2}$ nanoparticles using Staphylococcus aureus for antibacterial and antibiofilm applications. J Microbiol Exp 8(1):36-43

Lebeaux D, Chauhan A, Rendueles O, Beloin C (2013) From in vitro to in vivo models of bacterial biofilm related infections. Pathogens 2(2):288-356

Lee NY, Ko W-C, Hsueh P-R (2019) Nanoparticles in the treatment of infections caused by multidrug-resistant organisms. Front Pharmacol 10:1153

Li XZ, Nikaido H, Williams KE (1997) Silver-resistant mutants of Escherichia coli display active efflux of $\mathrm{Ag}+$ and are deficient in porins. J Bacteriol 179:6127-6132

Li P, Li J, Wu C, Wu Q, Li J (2005) Synergistic antibacterial effects of $\beta$-lactam antibiotic combined with silver nanoparticles. Nanotechnology 16:1912

Li Z, Greden K, Alvarez PJ, Gregory KB, Lowry GV (2010) Adsorbed polymer and NOM limits adhesion and toxicity of nano scale zerovalent iron to E. coli. Environ Sci Technol 44:3462-3467

Li M, Zhu L, Lin D (2011) Toxicity of ZnO nanoparticles to Escherichia coli: mechanism and the influence of medium components. Environ Sci Technol 45:1977-1983

Li S, Zhu T, Huang J, Guo Q, Chen G, Lai Y (2017) Durable antibacterial and UV-protective Ag/ $/ \mathrm{TiO}_{2} @$ fabrics for sustainable biomedical application. Int J Nanomed 12:2593-2606

Liao S, Zhang Y, Pan X, Zhu F, Jiang G, Liu Q, Cheng Z, Dai G, Wu G, Wang L, Chen L (2019) Antibacterial activity and mechanism of silver nanoparticles against multidrug-resistant Pseudomonas aeruginosa. Int J Nanomed 14:1469-1487

Liao Z, Zhang W, Qiao Z, Luo J, Ai Niwaer AE, Meng X, Wang H, Li X, Zuo F, Zhao Z (2020) Dopamine-assisted one-pot synthesis of gold nanoworms and their application as photothermal agents. J Colloid Interface Sci 562:81-90

Lin Z, Monteiro-Riviere NA, Riviere JE (2015) Pharmacokinetics of metallic nanoparticles. Wiley Interdiscip Rev Nanomed Nanobiotechnol 7:189-217

Linsley CS, Wu BM (2017) Recent advances in light-responsive on-demand drug delivery systems. Ther Deliv 8(2):89-107
Liu P, Duan W, Wang Q, Li X (2010) The damage of outer membrane of Escherichia coli in the presence of $\mathrm{TiO}_{2}$ combined with UV light. Colloids Surf B 78:171-176

Lopez-Carrizales M, Velasco KKI, Castillo C, Floves A, Magana M, Martinez-Castanon GA, Martinez-Gutierrez F (2018) In vitro synergism of silver nanoparticles with antibiotics as an alternative treatment in multiresistant uropathogens. Antibiotics 7:50

Ma BC, Ghasimi S, Landfester K et al (2016) Enhanced visible light promoted antibacterial efficiency of conjugated microporous polymer nanoparticles via molecular doping. J Mater Chem B 4:5112-5118

Madivoli ES, Kareru PG, Maina EG, Nyabola AO, Wanakai SI, Nyang'au JO (2019) Biosynthesis of iron nanoparticles using Ageratum conyzoides extracts, their antimicrobial and photocatalytic activity. SN Appl Sci 1(5):500

Malaikozhundan B, Vinodhini J, Kalanjiam MAR, Vinotha V, Palanisamy S, Vijayakumar S, Vaseeharan B, Mariyappan A (2020) High synergistic antibacterial, antibiofilm, antidiabetic and antimetabolic activity of withania Somnifera leaf extractassisted zinc oxide nanoparticle bioprocess. Biosyst Eng. https://doi.org/10.1007/500449-020-02346-0

Maliszewska I, Kałas W, Wysokiéska E, Tylus W, Pietrzyk N, Popko $\mathrm{K}$ et al (2018) Enhancement of photo-bactericidal effect of tetrasulfonated hydroxyaluminum phthalocyanine on $\mathrm{Pseu}$ domonas aeruginosa. Lasers Med Sci 33:79-88

Mandava K, Kadimcharla K, Keesara NR, Sumayya NF, Prathyusha B, Batchu UR (2017) Green synthesis of stable copper nanoparticles and synergistic activity with antibiotics. Indian J Pharm Sci 79(5):695-700

Manivasagan P, Khan F, Hoang G, Mondal S, Kim H, Doan VHM, Kim Y-M, Oh J (2019) Thiol chitosanwrapped gold nanoshells for near-infrared laser-induced photothermal destruction of antibiotic-resistant bacteria. Carbohydr Polym 225:115228

Maurer LL, Meyer JN (2016) A systematic review of evidence for silver nanoparticle-induced mitochondrial toxicity. Environ Sci Nano 3:311-322

Mba IE, Nweze EI (2020) The use of nanoparticles as alternative therapeutic agents against Candida infections: an up-to-date overview and future perspectives. World J Microbiol Biotech 36:163

Mba IE, Sharndama HC, Osondu-Chuka GO, Okeke OP (2021) Immunobiology and nanotherapeutics of severe acute respiratory syndrome 2 (SARS-CoV-2): a current update. Infect Dis. https://doi. org/10.1080/23744235.2021.1916071

Meeker DG, Jenkins SV, Miller EK, Beenken KE, Loughran AJ, Powless A, Muldoon TJ et al (2016) Synergistic photothermal and antibiotic killing of biofilm associated Staphylococcus aureus using targeted antibiotic-loaded gold nanoconstructs. ACS Infect Dis 2:241-250

Meza-villezcas A, Gallego-Hernandez AL, Yildiz FH, Jaime-Acuna DE, Raymond-Herrera O, Huerta-Saquero A (2019) Effect of antimicrobial nanocomposites on Vibrio cholera lifestyles: pellicle biofilm, planktonic and surface-attached biofilm. PLoS ONE 14(6):e0217869

Mocan L, Ilie I, Matea C, Tabaran F, Kalman E, Iancu C, Mocan T (2014) Surface plasmon resonance-induced photoactivation of gold nanoparticles as bactericidal agents against methicillinresistant Staphylococcus aureus. Int J Nanomed 9:1453-1461

Mohamed MA (2020) Myco-engineered gold nanoparticles from Jahnula aquatica coated with ampicillin/amoxicillin and their antibacterial and anticancer activity against cancer cells. Biotechnol Lett 42:151-170

Möhler JS, Sim W, Blaskovich MA, Cooper MA, Ziora ZM (2018) Silver bullets: a new lustre on an old antimicrobial agent. Biotechnol Adv 36(5):1391-1411 
Morgan DJ, Okeke IN, Laxminarayan R, Perencevich EN, Weisenberg S (2011) Non-prescription antimicrobial use worldwide: a systematic review. Lancet Infect Dis 11:692-701

Moteriya P, Padalia H, Chanda S (2017) Characterization, synergistic antibacterial and free radical scavenging efficacy of silver nanoparticles synthesized using Cassia roxburghii leaf extract. J Genet Eng Biotechnol 15(2):505-513

Muflikhun MA, Frommelt MC, Farman M, Chua AY, Santos GNC (2019) Structures mechanical properties and antibacterial activity of $\mathrm{Ag} / \mathrm{TiO}_{2}$ nanocomposite materials synthesized via HVPG technique for coating application. Heliyon 5:e01475

Munita JM, Arias CA (2016) Mechanisms of antibiotics resistance. Microbiol Spectr. https://doi.org/10.1128/microbiolspec. VMBF-0016-2015

Nabavizadeh M, Abbaszadegan A, Gholami A, Kadkhoda Z, Mirhadi H, Ghasemi Y, Safari A, Hemmateenejad B, Dorostkar S, Sharghi H (2017) Antibiofilm efficacy of positively charged imidazolium-based silver nanoparticles in Enterococcus faecalis using quantitative real-time PCR. Jundishapur J Microbiol. https://doi.org/10.5812/jjm.55616

Nathwani D, Raman G, Sulham K, Gavaghan M, Menon V (2014) Clinical and economic consequences of hospital acquired resistant and multidrug-resistant Pseudomonas aeruginosa infections: a systematic review and meta-analysis. Antimicrob Resist Infect Control 3(32):1-16

Nejabatdoust A, Zamani H, Salehzadeh A (2019) Functionalization of $\mathrm{ZnO}$ nanoparticles by glutamic acid and conjugation with thiosemicarbazide alters expression of efflux pump genes in multiple drug-resistant Staphylococcus aureus strains. Microb Drug Resist 25(7):966-974

Nguyen N-YT, Gruelling N, Wetteland CL, Rosario R, Liu H (2018) Antimicrobial activities and mechanisms of magnesium oxide nanoparticles $(\mathrm{nMgO})$ against pathogenic bacteria, yeasts, and biofilms. Sci Rep 8:16260

Nino-Martinez N, Orozco MFS, Martinez-Castanon G-A, Mendez FT, Ruiz F (2019) Molecular mechanisms of bacterial resistance to metal and metal oxide nanoparticles. Int J Mol Sci 20:2808

Nour El Din S, El-Tayeb TA, Abou-Aisha K, El-Azizi M (2016) In vitro and in vivo antimicrobial activity of combined therapy of silver nanoparticles and visible blue light against Pseudomonas aeruginosa. Int J Nanomed 11:1749-1758

Nunez YAR, Castro RI, Arenas FA, Lopez-Cabana ZE, Carreno G, Carasco-Sanchez V, Marican A, Villasenor J, Vargas E, Santos LS, Duran-Lara EF (2019) Preparation of hydrogel/silver nanohybrids mediated by tunable-size nanoparticles for potential antibacterial applications. Polymers 11:716

Ogungemi SO, Zhang F, Abdallah Y, Zhang M, Wang Y, Sun G, Qiu W, Li B (2019) Biosynthesis and characterization of magnesium oxide and manganese dioxide nanoparticles using Matricaria Chamomilla leaf extract and its inhibitoru effect on Acidovorax oryzae strain RS-2. Artif Cells Nanomed Biotechnol 47(1):2230-2239

Osonga FJ, Akgul A, Yazgan I, Akgul A, Eshun GB, Sakhaee L, Sadik OA (2020) Size and shape-dependent antimicrobial activities of silver and gold nanoparticles: a model study as potential fungicides. Molecules 25:2682

Palomo-Siguero M, Gutiérrez AMA, Pérez-Conde C, Madrid Y (2016) Effect of selenite and selenium nanoparticles on lactic bacteria: a multi-analytical study. Microchem J 126:488-495

Panacek A, Smekalova M, Kilianova M, Prucek R, Bogdanova K, Vecerova R, Kolar M, Havrdova M, Plaza GA, Chojniak J, Zboril R, Kvitek L (2015) Strong and nonspecific synergistic antibacterial efficiency of antibiotics combined with silver nanoparticles at very low concentrations showing no cytotoxic effect. Molecules 21:E26
Panacek A, Kvitek L, Smekalova M, Vecerova R, Kolar M, Roderova M, Dycka F, Sebela M, Prucek R, Tomanec O, Zboril R (2018) Bacterial resistance to silver nanoparticles and how to overcome it. Nature Nanotechnol 13:65-71

Pandiyan N, Murugesan B, Arumugam M, Sonamuthu J, Samayanan S, Mahalingam S (2019) Ionic liquid. A greener templating agent with Justicia adhatida plant extract assisted green synthesis of morphologically improved $\mathrm{Ag}-\mathrm{Au} / \mathrm{ZnO}$ nanostructures and its antibacterial and anticancer activities. J Photochem Photobiol B Biol 198:111559

Pasupathy S, Rajamanickam M (2019) Synthesis of pure and bio modified calcium oxide $(\mathrm{CaO})$ nanoparticles using waste chicken egg shells and evaluation of its antibacterial activity. Int J Pharma Sci Res 1:230

Patra JK, Baek KH (2017) Antibacterial activity and synergistic antibacterial potential of biosynthesized silver nanoparticles against food borne pathogenic bacteria along with its anticandidal and antioxidant effects. Front Microbiol 8:167

Petros RA, DeSimone JM (2010) Strategies in the design of nanoparticles for therapeutic applications. Nat Rev Drug Discov 9(8):615-627

Pranjali L, Meher MK, Raj R, Prasad N, Poluri KM, Kumar D, Guleria A (2019) Physiochemical and antibacterial properties of PEGylated zinc oxide nanoparticles dispersed in peritoneal dialysis fluid. ACS Omega 4:19255-19264

Qi M, Chi M, Sun X, Xie X, Weir MD, Oates TW, Zhou Y, Wang L, Bai Y, Xu HHK (2019) Nanomaterial-based antibacterial photodynamic therapies to combat oral biofilms and infectious diseases. Int J Nanomed 14:6937-6956

Qing Y, Cheng L, Li R, Liu G, Zhang Y, Tang X, Wang J, Liu H, Qin Y (2018) Potential antibacterial mechanism of silver nanoparticles and the optimization of orthopedic implants by advanced modification technologies. Int J Nanomed 13:3311-3327

Qiu Z, Shen Z, Qian D, Jin M, Yang D, Wang J, Zhang B, Yang Z, Chen Z, Wang X (2015) Effects of nano-TiO2 on antibiotic resistance transfer mediated by RP4 plasmid. Nanotoxicology 9:895-904

Qiu M, Wang D, Liang W, Liu L, Zhang Y, Chen X, Sang DK et al (2018) Novel concept of the smart NIR-light-controlled drug release of black phosphorus nanostructure for cancer therapy. Proc Natl Acad Sci USA 115:501-506

Rajan AS, Khan A, Asrar S, Raza H, Das RK, Sahu NK (2019) Synthesis of $\mathrm{ZnO} / \mathrm{Fe} 3 \mathrm{O} 4 / \mathrm{rGo}$ nanocomposites and evaluation of antibacterial activities towards $E$. coli and $S$. aureus. IET Nanobiotchnol 13(7):682-687

Ramalingam V, Sundaramahalingam S, Rajaram R (2019) Sizedependent antimycobacterial activity of titanium oxide nanoparticles against mycobacterium tuberculosis. J Mater Chem B 7:4338-4346

Ramezani P, Abnous K, Taghdisi SM, Zahiri M, Ramezani M, Alibolandi M (2020) Targeted MMP-2 responsive chimeric polymersomes for therapy against colorectal cancer. Colloids Surf B 193:111135

Ran X, Du Y, Wang Z, Wang H, Pu F, Ren J, Qu X (2017) Hyaluronic acid-templated Ag nanoparticles/graphene oxide composites for synergistic therapy of bacteria infection. ACS Appl Mater Interfaces 9:19717-19724

Rao TN, Babji RP, Ahmad N, Khan RA, Hassan I, Shahzad SA, Husain FM (2019) Green synthesis and structural classification of Acacia nilotica mediated-silver doped titanium oxide (Ag/ $\mathrm{TiO}_{2}$ ) spherical nanoparticles: assessment of its antimicrobial and anticancer activity. Saudi J Biol Sci 26:1385-1391

Rasheed T, Bilal M, Li C, Iqbal HMN (2017) Biomedical potentialities of Taraxacum officinale-based nanoparticles biosynthesized using methanolic leaf extract. Curr Pharma Biotechnol $18: 14$ 
Rathnayake K, Patel U, Pham C, McAlpin A, Budisalich T, Jayawardena SN (2020) Targeted delivery of antibiotic therapy to inhibit pseudomonas aeruginosa using lipid-coated mesoporous silica core-shell nanoassembly. ACS Appl Bio Mater 3:6708-6721

Rattanata N, Klaynongsruang S, Leelayuwat C, Limpaiboon T, Lulitanond A, Boonsiri P, Chio-Srichan S, Soontaranon S, Rugmai S, Daduang J (2016) Gallic acid conjugated with gold nanoparticles: antibacterial activity and mechanism of action on foodborne pathogens. Int J Nanomed 27(11):3347-3356

Ray PC, Khan SA, Singh AK, Senapati D, Fan Z (2012) Nanomaterials for targeted detection and photothermal killing of bacteria. Chem Soc Rev 41:3193-3209

Raza M, Kanwal Z, Rauf A, Sabri A, Riaz S, Naseem S (2016) Sizeand shape-dependent antibacterial studies of silver nanoparticles synthesized by wet chemical routes. Nanomaterials 6:74

Rehman S, Jermy BR, Akhtar S, Borgio JF, Azeez SA, Ravinayagam V, Jindan RA, Alsalem ZH, Buhameid A, Gani A (2019) Isolaton and characterization of novel thermophile, Bacillus haynesii, applied for the green synthesis of Zno nanoparticles. Artif Cell Nanomed Biotechnol 47(1):2072-2082

Roca I, Akova M, Baquero F, Carlet J, Cavaleri M, Coenen S, Cohen J et al (2015) The global threat of antimicrobial resistance: science for intervention. N Microbes N Infect 6:22-29

Rodriguez-Serrano C, Guzman-Moreno J, Angeles-chavez C, Rodriguez-Gonzalez V, Ortega-Sigala JJ, Ramirez-Santoyo RM, Vidales-Rodriguez LE (2020) Biosynthesis of silver nanoparticles by Fusarium scirpi and its poential as antimicrobial agent against uropathogenic Escherichia coli biofilm. PLoS ONE 15(3):e0230275

Roy AS, Parveen A, Koppalkar AR, Prasad MA (2010) Effect of nanotitanium dioxide with different antibiotics against methicillinresistant Staphylococcus aureus. J Biomater Nanobiotechnol 1:37

Saginur R, Stdenis M, Ferris W, Aaron SD, Chan F, Lee C, Ramotar K (2006) Multiple combination bactericidal testing of staphylococcal biofilms from implant-associated infections. Antimicrob Agents Chemother 50(1):55-61

Sajjad S, Uzair B, Shaukat A, Jamshed M, Leghari SAK, Ismail M, Mansoor Q (2019) Synergistic evaluation of $\mathrm{AgO}_{2}$ nanoparticles with ceftriaxone against CTXM and blaSHV genes positive ESBL producing clinical strains of uropathogenic E. Coli. IET Nanobiotechnol 13(4):435-440

Sanchez CJ, Mende K, Beckius ML, Akers KS, Romano DR, Wenke JC, Murray CK (2013) Biofilm formation by clinical isolates and the implications in chronic infections. BMC Infect Dis 13:47

Saravanakumar K, Jeevithan E, Hu X, Chelliah R, Oh D-H, Wang M-H (2020) Enhanced anti-lung carcinoma and anti-biofilm activity of fungal molecules conjugated with $\beta$-D-glucan from barley. $\mathrm{J}$ Photochem Photobiol B 203:11728

Saruchi, Thakur P, Kumar V (2019) Kinetics and thermodynamics studies for removal of methylene blue dye by biosynthesized copper oxide nanoparticles and its antibacterial activity. J Environ Health Sci Eng 17:367-376

Sarwar S, Ali A, Pal M, Chakrabarti P (2017) Zinc oxide nanoparticles provide anti-cholera activity by disrupting the interaction of cholera toxin with the human GM1 receptor. J Biol Chem 292:18303-18311

Sathishkumar G, Logeshwaran V, Sarathbabu S, Jha PK, Jeyaraj M, Rajkuberan C, Senthilkumar N, Sivaramakrishnan S (2018) Green synthesis of magnetic $\mathrm{Fe} 3 \mathrm{O} 4$ nanoparticles using Couroupita guianensis Aubl. Fruit extract for their antibacterial and cytotoxicity activities. Artif Cells Nanomed Biotechnol 46(3):589-598

Selvaraj RCA, Rajendra M, Nagaiah HP (2019) Re-potentiation of $\beta$-lactam antibiotic by synergistic combination with biogenic copper oxide nanocubes against biofilm forming multidrugresistant bacteria. Molecules 24:3055

Sengupta J, Ghosh S, Datta P, Gomes A, Gomes A (2014) Physiologically important metal nanoparticles and their toxicity. J Nanosci Nanotechnol 14:990-1006

Shahbazi E, Morshedzadeh F, Zaeifi D (2019) Bacteriostatic potency of $\mathrm{Fe} 2 \mathrm{O} 3$ against Enterococcus faecalis in synergy with antibiotics by DDST method. Avicenna J Med Biotech 11(2):176-179

Shahverdi AR, Fakhimi A, Shahverdi HR, Minaian S (2007) Synthesis and effect of silver nanoparticles on the antibacterial activity of different antibiotics against Staphylococcus aureus and Escherichia coli. Nanomed Nanotechnol Biol Med 3:168-171

Shaikh S, Nazam N, Rizvi SMD, Ahmad K, Bait MH, Lee EJ (2019) Choice. Mechanistic insights into the antimicrobial actions of metallic nanoparticles and their implication for multi drug resistance. Int J Mol Sci 20:2468

Shamaila S, Zafar N, Riaz S, Sharif R, Nazir J, Naseem S (2016) Gold nanoparticles: an efficient antimicrobial agent against enteric bacterial human pathogen. Nanomaterials 6:71

Sharma N, Jandaik S, Kumar S (2016) Synergistic activity of doped zinc oxide nanoparticles with antibiotics: ciprofloxacin, amoxicillin, fluconazole and amphotericin B against pathogenic microorganisms. An Acad Bras Cienc 88(3):1689-1698

Sharma G, Soni R, Jasuja ND (2017) Photo assisted synthesis of magnesium oxide nanoparticles with swertia chirayaita. J Taibah Univ Sci 11:471-477

Shobha G, Vinutha M, Ananda S (2014) Biological synthesis of copper nanoparticles and its impact-a review. Int J Pharma Sci Invent 3(8):28-38

Siemer S, Westmeier D, Barz M, Eckrich J, Wünsch D, Seckert C, Thyssen C, Schilling O, Hasenberg M, Pang C (2019) Biomolecule-corona formation confers resistance of bacteria to nanoparticle-induced killing: implications for the design of improved nanoantibiotics. Biomaterials 192:551-559

Singh S, Park I, Shin Y, Lee Y (2015) Comparative study on antimicrobial efficiency of $\mathrm{AgSiO} 2, \mathrm{ZnAg}$, and $\mathrm{Ag}-\mathrm{Zeolite}$ for the application of fishery plastic container. J Mater Sci Eng 4:2169. https://doi.org/10.4172/2169-0022.1000180

Singh H, Du J, Singh P, Yi TH (2018) Ecofriendly synthesis of silver and gold nanoparticles by Euphrasia officinalis leaf extract and its biomedical applications. Artif Cells Nanomed Biotechnol 46(6): 1163-1170

Singh A, Joshi NC, Ramola M (2019) Magnesium oxide nanoparticles (MgONps): green synthesis, characterizations and antimicrobial activity. Res J Pharm Tech 12(10):4644-4646

Singh R, Cheng S, Singh S (2020) Oxidative stress-mediated genotoxic effect of zinc oxide nanoparticles on Deinococcus radiodurans. 3 Biotech 10:66

Smitha SL, Gopchandran KG (2013) Surface enhance raman scattering, antibacterial and antifungal active triangular gold nanoparticles spectromchim. Spectrochim Acta A 102:114-119

Sriram MI, Kalishwaralal K, Barathmanikanth S, Gurunathani S (2012) Size-based cytotoxicity of silver nanoparticles in bovine retinal endothelial cells. Nanosci Methods 1:56-77

Sueoka K, Chikama T, Latief MA, Ko JA, Kiuchi Y, Sakaguchi T et al (2018) Time-dependent antimicrobial effect of photodynamic therapy with TONS 504 on Pseudomonas aeruginosa. Lasers Med Sci 33:1455-1460

Supraja N, Prasad TNVKV, Krishna TG, David E (2016) Synthesis, characterization and evaluation of the antimicrobial efficacy of Boswellia ovalifoliolata stem barks extract a existed zinc oxide nanoparticles. Appl Nanosci 6:581-590

Surwade P, Ghildyal C, Weikel C, Luxton T, Peloquin D, Fan X, Shah V (2019) Augumented antibacterial activity of ampicillin with silver nanoparticles against methicillin-resistant Staphylococcus aureus (MRSA). J Antibiot (Tokyo) 72(1):50-53 
Tăbăran A-F, Matea CT, Mocan T, Tăbăran A, Mihaiu M, Iancu C, Mocan L (2020) Silver nanoparticles for the therapy of tuberculosis. Int J Nanomed 15:2231-2258

Tamayo LA, Zapata PA, Vejar ND, Azócar MI, Gulppi MA, Zhou X, Thompson GE, Rabaghati FM, Paez MA (2014) Release of silver and copper nanoparticles from polyethylene nanocomposites and their penetration into Listeria monocytogenes. Mater Sci Eng C 40:24-31

Tao C (2018) Antimicrobial activity and toxicity of gold nanoparticles: research, challenges and prospects. Lett Appl Microbiol 67:537-543

Thang DC, Wang Z, Lu X, Xing B (2019) Precise cell behaviors manipulation through light-responsive nano-regulators: recent advance and perspective. Theranostics 9(11):3308-3340

Torchilin VP (2014) Multifunctional, stimuli-sensitive nanoparticulate systems for drug delivery. Nat Rev Drug Discov 13(11):813-827

Umar H, Kavaz D, Rizaner N (2019) Biosynthesis of zinc oxide nanoparticles using Albizia lebbeck stem bark and evaluation of its antimicrobial, antioxidant, and cytotoxic activities on human breast cancer cell lines. Int J Nanomed 14:87-100

Vergheese M, Vishal SK (2018) Green synthesis of magnesium oxide nanoparticles using Trigonella foenum-graecum leaf extract and its antibacterial activity. J Pharmacogn Phytochem 7(3):1193-1200

Wan G, Ryan L, Yin Y, Yang T, Ge M, Cheng X (2016) Effects of silver nanoparticles in combination with antibiotics on the resistant bacteria Acinetobacter baumannii. Int J Nanomed 11:3789

Wang S, Lawson R, Ray PC, Yu H (2011) Toxic effects of gold nanoparticles on Salmonella typhimurium bacteria. Toxicol Ind Health 227:547-554

Wang AZ, Langer R, Farokhzad OC (2012) Nanoparticle delivery of cancer drugs. Annu Rev Med 63:185-198

Wang Q, Kang F, Gao Y, Mao X, Hu X (2016) Sequestration of nanoparticles by an EPS matrix reduces the particle-specific bactericidal activity. Sci Rep 6:21379

Wang L, Hu C, Shao L (2017a) The antimicrobial activity of nanoparticles: present situation and prospects for the future. Int J Nanomed 12:1227-1249

Wang Y, Harrington OD, Wang Y, Murray CK, Hamblin MR, Dai T (2017b) In vivo investigation of antimicrobial blue light therapy for multidrugresistant Acinetobacter baumannii burn infections using bioluminescence imaging. J Vis Exp 122:e54997

Wang X, Yang F, Zhao J, Xu Y, Mao D, Zhu X, Luo Y, Alvarez P (2018) Bacterial exposure to $\mathrm{ZnO}$ nanoparticles facilitates horizontal transfer of antibiotic resistance genes. NanoImpact 10:61-67

Wei L, Lu J, Xu H, Patel A, Chen ZS, Chen G (2015) Silver nanoparticles: synthesis, properties, and therapeutic applications. Drug Discov Today 20:595-601

Wei X, Liu L, Guo X, Wang Y, Zhao J, Zhou S (2018) Light-activated ros-responsive nanoplatform co-delivering apatinib and doxorubicin for enhanced chemo-photodynamic therapy of multidrugresistant tumors. ACS Appl Mater Interfaces 10:17672-17684

World Health Organization (WHO) (2015) Antibiotic resistance: multicountry public awareness survey. https://www.who.int/antim icrobial-resistance/publications/baselinessurveynov2015/en/. Accessed 8 Dec 2020
Wu P, Xie R, Imlay K, Shang JK (2010) Visible-light-induced bactericidal activity of titanium dioxide codoped with nitrogen and silver. Environ Sci Technol 44:6992-6997

Wu S, Li A, Zhao X, Zhang C, Yu B, Zhao N, Xu F-J (2019) Silica coated gold-silver nanocages as photothermal antibacterial agents for combined anti-infective therapy. ACS Appl Mater Interfaces 11(19):17177-17183

Wypig M, Czarnecka J, Swiecimska M, Dahm H, Rai M, Golinska P (2018) Synthesis, characterization and evaluation of antimicrobial and cytotoxic activities of biogenic silver nanoparticles synthesized from Streptomyces xinghaiensis OF1 strain. World J Biotechnol 34:23

Xie Y, Zheng W, Jiang X (2020) Near-infrared light-activated phototherapy by gold nanoclusters for dispersing biofilms. ACS Appl Mater Interfaces 12:9041-9049

Yang Y, Mathieu JM, Chattopadhyay S, Miller JT, Wu T, Shibata T, Guo W, Alvarez PJ (2012) Defense mechanisms of Pseudomonas aeruginosa $\mathrm{PAO} 1$ against quantum dots and their released heavy metals. ACS Nano 6:6091-6098

Yang T, Wang D, Liu X (2019) Assembled gold nanorods for the photothermal killing of bacteria. Colloids Surf B 173:833-841

Yetisgin AA, Cetinel S, Zuvin M, Kosar A, Kutlu O (2020) Therapeutic nanoparticles and their targeted delivery application. Molecules 25:2193

Yu S, Liu J, Yin Y, Shen M (2018) Interactions between engineered nanoparticles and dissolved organic matter: a review on mechanisms and environmental effects. J Environ Sci 63:198-217

Yu Z, Li Q, Wang J, Yu Y, Wang Y, Zhou Q, Li P (2020) Reactive oxygen species-related nanoparticle toxicity in the biomedical field. Res Lett 15:115

Yuan L, Lei T, Zhenduo C, Xianjin Y, Yufeng Z, Kelvin Y, Kwok W, Paul CK, Wu S (2018) Rapid sterilization and accelerated wound healing using $\mathrm{Zn} 2+$ and graphene oxide modified g-C3N4 under dual light irradiation. Adv Funct Mater 28:1800299

Zaidi S, Misba L, Khan AU (2017) Nano-therapeutics: a revolution in infection control in post antibiotic era. Nanomedicine 13:2281-2301

Zazo H, Colino CI, Lanao JM (2016) Current applications of nanoparticles in infectious diseases. J Control Release 224:86-102

Zhang Y, Gu AZ, Xie S, Li X, Cen T, Li D, Cgen J (2018) Nanometal oxides induce antimicrobial resistance via radical-mediated mutagenesis. Environ Int 121:1162-1171

Zhao Y, Lu Z, Dai X, Wei X, Yu Y, Chen X et al (2018) Glycomimeticconjugated photosensitizer for specific Pseudomonas aeruginosa recognition and targeted photodynamic therapy. Bioconj Chem 29:3222-3230

Zhao Y-Q, Sun Y, Zhang Y, Ding X, Zhao N, Yu B, Zhao H, Duan S, Xu F-J (2020) Well-defined gold nanorod/polymer hybrid coating with inherent antifouling and photothermal bactericidal properties for treating an infected hernia. ACS Nano 14:2265-2275

Publisher's Note Springer Nature remains neutral with regard to jurisdictional claims in published maps and institutional affiliations. 